\title{
Morphology and life cycle of an epiphytic pherusellid ctenostome bryozoan from the Mediterranean Sea
}

\author{
Sebastian Decker ${ }^{1} \cdot$ Andreas Wanninger $^{1}$ (D) $\cdot$ Thomas Schwaha $^{1}$ (D)
}

Received: 12 March 2020 / Accepted: 29 May 2020 / Published online: 11 June 2020

(C) The Author(s) 2020

\begin{abstract}
The epiphytic community on the endemic seagrass Posidonia oceanica from the Mediterranean Sea is well studied, but still harbors some little investigated epiphytic bryozoans. Numerous, yet always small colonies of Pherusella sp. were recently encountered in the Northern Adriatic Sea. The aim of this study was to generate data on the life history, colonial development, and reproduction of the Mediterranean population of this Pherusella species in order to gain a better understanding of the biology of this understudied species. The morphology of adult zooids was also studied due to the lack of recent data on the family with state-of-the-art techniques. Long-term observation shows that this species is highly adapted to an epiphytic life cycle with short generation time throughout the year. First laboratory cultures appear promising in establishing a reliable model system for developmental and ecological studies. Larvae are easily obtainable, and metamorphosis and colonial growth patterns are documented here for the first time. The morphology of adults shows distinct similarities with other pheruselllids and, along with the neuromuscular system, is similar to other alcyonidioideans supporting the close relationship of these taxa. This study constitutes one of the first long-time observations of the life cycle and colonial growth of a pherusellid bryozoan, including morphological data about the neuromuscular system of an otherwise incompletely known group of bryozoans. Pherusella sp. appears to be a promising candidate for future studies since it is easy to collect and maintain under laboratory conditions as well as to obtain different developmental stages.
\end{abstract}

Keywords Ctenostomata $\cdot$ Development $\cdot$ Posidonia $\cdot$ Pseudocyphonautes $\cdot$ Pherusella

\section{Introduction}

The lophotrochozoan phylum Bryozoa comprises about 5900 extant and more than 15,000 extinct species (Bock and Gordon 2013). As aquatic sessile animals, they colonize various substrates in predominantly marine environments with a small fraction restricted to freshwater habitats. Most bryozoans generate colonies of small repetitive units (zooids) that undergo periodic asexual budding for colonial growth. Bryozoan zooids consist of a polypide comprising the ciliated tentacle crown, the lophophore, digestive tract and associated

Electronic supplementary material The online version of this article (https://doi.org/10.1007/s13127-020-00443-2) contains supplementary material, which is available to authorized users.

Thomas Schwaha

thomas.schwaha@univie.ac.at

1 Department of Evolutionary Biology, Integrative Zoology, University of Vienna, Althanstraße 14, 1090 Vienna, Austria tissues, and a cystid (Schwaha 2019a). The latter represents the body wall which can be supported by various cuticular or calcified reinforcements. The lophophore is circular in all marine representatives, while the freshwater-inhabiting phylactolaemates show a distinct horseshoe-shaped lophophore, including an epistome at its base (Mukai et al. 1997). Bryozoans are divided into two clades: the Phylactolaemata and the Myolaemata (Schwaha et al. 2020), the latter comprising the Stenolaemata and Gymnolaemata. Within the Gymnolaemata, the cheilostomes account for the majority of bryozoan species. With $\sim 5000$ described species, cheilostomes are the most diverse and abundant group of bryozoans and possess a calcareous skeleton and a characteristic operculum (Ryland 2005; Bock and Gordon 2013). In contrast, only $\sim 350$ species have been described from the uncalcified ctenostome Gymnolaemata (Schwaha 2019b). Ctenostomes are a paraphyletic group with cheilostomes that originated from a ctenostome-like ancestor (Todd 2000; Waeschenbach et al. 2012). Traditionally, ctenostomes were divided into the "Carnosa" and "Stolonifera," with the 
carnosans showing simple box-shaped zooids and sheet-like encrusting colonies, whereas the stoloniferans have cylindrical zooids interconnected by kenozooidal stolons (Hayward 1985). The terms are today used for describing general growth patterns, but do not reflect any phylogenetic relationships (Jebram 1973a; Todd 2000; Waeschenbach et al. 2012). The alcyonidioid superfamily is often considered an early branching clade within ctenostomes because of their encrusting carnosan-like colony type (Waeschenbach et al. 2012).

Approximately five to six families are currently recognized in the Alcyonidioidea (Schwaha 2019b). Of these, Pherusellidae and Flustrellidridae are the only ones that share the unique pseudocyphonautes larval type (Reed 1991). Pherusellidae is characterized by a quadrangular aperture, which is considered an apomorphic character of this family (Schwaha 2019b). The Pherusellidae includes three species within one genus, Pherusella tubulosa (Ellis \& Solander, 1786), Pherusella flabellaris (Kirkpatrick, 1890), and Pherusella brevituba Soule 1951, which differ in different peristomial length and tentacle numbers (Prouho 1892; Soule 1951; Zabala and Maluquer 1988). Recently, small colonies of Pherusella cf. brevituba encrusting the leaves of the seagrass Posidonia oceanica (L.) Delille, 1813 were found around Sicily (Italy) (Chimenz Gusso et al. 2004; Chimenz Gusso and D'Hondt 2005). Preliminary observations in the Northern Adriatic Sea showed that such colonies were incredibly abundant and commonly carried brooded embryos. The easy access to adult and embryonic material renders this species interesting as potential model for developmental and experimental studies. Owing to the lack of recent data concerning the life cycle, growth, and morphology of any pherusellid ctenostome, the aim of this study was to investigate the life cycle, reproduction, and adult morphology of Pherusella sp. in more detail.

\section{Material and methods}

\section{Collection and fixation of specimens}

Colonies of Pherusella sp. were found exclusively on the leaves of the seagrass Posidonia oceanica. Therefore, several leaves were collected and observed under laboratory conditions year round from 2017 to 2019. Specimens of Pherusella sp. were collected at two different sites along the Croatian shoreline close to the city of Pula. In the bay of Soline $\left(44^{\circ}\right.$ $50^{\prime} 55.1^{\prime \prime} \mathrm{N}, 13^{\circ} 49^{\prime} 51.2^{\prime \prime} \mathrm{E}$ ), the seagrass meadow is in a depth ranging from 13 to $15 \mathrm{~m}$ and at the second site in the bay of Valovine ( $\left.44^{\circ} 51^{\prime} 34.4^{\prime \prime} \mathrm{N}, 13^{\circ} 48^{\prime} 46.7^{\prime \prime} \mathrm{E}\right)$ in a depth of 2.5 to $4 \mathrm{~m}$. Selected colonies were either fixed or kept under laboratory conditions for further investigations. Fixation was carried out either in $4 \%$ paraformaldehyde (PFA) in $0.1 \mathrm{M}$ phosphate buffer (PB) or in $2.5 \%$ glutaraldehyde (GA) in $0.1 \mathrm{M} \mathrm{PB}(\mathrm{pH}=7.4)$. Afterwards, samples were washed three to four times for $15 \mathrm{~min}$ each in $0.1 \mathrm{M} \mathrm{PB}$ and stored in $0.1 \mathrm{M}$ $\mathrm{PB}$ with the addition of $0.1 \% \mathrm{NaN}_{3}$ at $4{ }^{\circ} \mathrm{C}$ until further analysis. Alternatively, some specimens were fixed and stored in $96 \%$ ethanol. Live colonies were kept in a $40-1$ seawater tank. Observation and documentation of living specimens was performed using a Nikon J1 camera (Nikon, Tokyo, Japan) mounted on a Wild M420 stereomicroscope (Wild Heerbrugg, Heerbrugg, Switzerland).

\section{Taxonomic state of Pherusella sp.}

The current species of this study is the same species first observed in Sicily in 2004 (Chimenz Gusso et al. 2004) and currently assigned as Pherusella brevituba (see also Rosso and Di Martino 2016). However, our long-term observations during the current study revealed that numerous characters merit assignment of a new species. The species description and taxonomic revision of the entire family is currently in progress and requires a separate publication. The latter will revise the entire family Pherusellidae including the description of two new species and the first study of holotype material of $P$. flabellaris. Consequently, the new species of the current study remains designated as Pherusella sp.

\section{Cultivation of colonies and larval settlement}

Live colonies were kept in a 40-1 seawater tank with an air diffusion system for water circulation and no filter system. Every 4 days, two-thirds of the seawater was exchanged with fresh natural seawater. The water temperature was monitored and adjusted according to the ambient seawater temperature in Croatia from 14 to $26^{\circ} \mathrm{C}$. Every 2 days, $1 \mathrm{ml}$ of a phytoplankton stock solution (MICROBE-LIFT PhytoPlus, Ecological Laboratories Inc., Island Park, NY, USA) was introduced to supply mature colonies with food. Several colonies with developing larvae were kept separately in small containers until larval release. To ensure stable conditions, the seawater within the containers was exchanged every $12 \mathrm{~h}$ with seawater of the tank. After larval release, the mother colony was removed from the container and cover slips were introduced as substrate for the larvae. After successful settlement onto a cover slip, the developing ancestrulae were mounted and kept in the 40-1 tank for further documentation every $24 \mathrm{~h}$.

\section{Adult morphology}

\section{Immunocytochemistry and confocal laser scanning microscopy}

Specimens fixed in $4 \%$ paraformaldehyde were used for fluorescence labeling and first treated with a phosphate 
buffer solution containing $2 \%$ Triton X-100 and 2\% DMSO (PBT) overnight at room temperature to increase tissue permeability. Unspecific binding sites were blocked using normal goat serum (NGS) diluted in PBT in a concentration of 1:60 and incubated overnight at room temperature. Primary antibodies against acetylated alpha-tubulin (Sigma Aldrich, St. Louis, MO, USA) were diluted in PBT in a concentration of 1:500 and against serotonin in a concentration of 1:800, respectively, followed by incubation overnight at room temperature. The following day, samples were washed five times in PB for $15 \mathrm{~min}$ each. Incubation with secondary antibodies containing the fluorochrome was performed in a concentration of 1:300 in PBT. Secondary antibodies were raised in goat against either mouse (AlexaFluor 568, Invitrogen, Carlsbad, CA) or rabbit (AlexaFluor633, Invitrogen). For F-actin-labeling, the fluorescent stain AlexaFluor 488 phalloidin (Invitrogen, Carlsbad, CA, USA) was diluted in PBT in a concentration of 1:100. In addition, cell nuclei were stained with DAPI in a concentration of 1:100 in PBT. Secondary antibodies, phalloidin, and DAPI incubation were done simultaneously overnight at room temperature. The following day, samples were rinsed five times for 15 min each in PB before mounted on microscope slides using Flouromount $\mathrm{G}$ (Southern Biotec, Birmingham, LA, USA). Mounted samples were stored at $4{ }^{\circ} \mathrm{C}$ before further investigation. Confocal scans were generated with a Leica SP5II confocal laser scanning microscope (Leica Microsystems, Wetzlar, Germany). Stacks were edited with the reconstruction software Amira version 6.3 (Mercury Computer Systems, Chelmsford, MA, USA) or with the ImageJ package Fiji version 1.51 (Schindelin et al. 2012).

\section{Sectioning and histological analysis}

Specimens fixed in $2.5 \%$ glutaraldehyde were first dehydrated in a graded ethanol series and embedded into Agar Low Viscosity Resin (LVR, Agar Scientific Ltd., Stansted, UK) using acetone as intermediate. Ribbons of serial semithin sections $(1 \mu \mathrm{m}$ thickness) were produced using a Leica UC6 ultramicrotome (Leica Microsystems GmbH, Wetzlar, Germany) and a Histo-Jumbo diamond knife (Diatome AG, Biel, Switzerland). Sections were stained with toluidine blue for a few seconds at $60^{\circ} \mathrm{C}$. Serial sections were photographed using a Nikon Eclipse Ni-U light microscope (Nikon, Tokyo, Japan). For image processing, Photoshop CS5 Extended version 12.0 (Adobe, San José, CA, USA) was used to reduce image size and for conversion into grayscale. Afterwards, the modified image stack was imported into the visualization and reconstruction software Amira 6.3 (Thermo Fisher Scientific, Waltham, MA, USA).

\section{Scanning electron microscopy}

Specimens fixed in $2.5 \%$ glutaraldehyde were first dehydrated in a series of gradually increasing acetone concentration (from 70 to $100 \%$ ). All samples were kept in $100 \%$ acetone until critical point drying (CPD) was applied with a Leica EM CPD300 critical point dryer. Afterwards, samples were mounted on SEM stubs using a conductive carbon tape followed by gold sputtering for $120 \mathrm{~s}$ using the sputter coater JEOL JFC-2300HR (JEOL, Akishima, Tokyo, Japan). Coated samples were investigated either with a Philips XL30 (Phillips, Amsterdam, Netherlands) or a JEOL IT 300 (JEOL, Akishima, Tokyo, Japan) scanning electron microscope.

\section{Results}

\section{Autozooidal morphology}

Zooids of Pherusella sp. are oval and flat-like discs exclusively encrusting the surface of the leaves of the seagrass Posidonia oceanica (Fig. 1a, b, d). When colonies grow by asexual budding, the shape of zooids can change to a more rectangular or hexagonal appearance (Fig. 2c, d). The cystid is uncalcified but chitinous. The cystid walls are almost completely translucent, rendering the polypide visible even when retracted. Older zooids can get light brown to yellowish in color if not covered by epiphytes. The ancestrula can be identified by the remains of the larval valves as ridges on the frontal wall. While settling, the larva spreads its two valves laterally, which leads to the formation of an elliptic structure about $300 \mu \mathrm{m}$ in length and $250 \mu \mathrm{m}$ in width. These ridges will remain on the frontal wall of the ancestrula throughout its ontogeny (Fig. 1a, b, d, e). Autozooids reach approximately $800 \mu \mathrm{m}$ in length and about $600 \mathrm{in}$ width. Although similar in shape, the size of zooids can vary in older colonies by showing a reduced size up to one third in length (Figs. 1a, b, d; and $2 \mathrm{c}, \mathrm{d}$ ). The orifice or aperture (used as synonym in this case, see Schwaha 2019a) is located on an elongated peristome with an approximate height of about $150 \mu \mathrm{m}$. The aperture itself is about $140 \mu \mathrm{m}$ in length and about $75 \mu \mathrm{m}$ in width and is characterized by a quadrangular shape and four prominent folds, which continue from the edges toward the center of the aperture (Fig. 1b-d, f). In the apertural area, the cystid wall continues as distinct vestibular wall, which is visible as light brown reinforcement in the interior of the peristome (Fig. 1a, b). The lophophore contains 19-21 delicate tentacles that have a length of about $280 \mu \mathrm{m}$. When retracted, the lophophore lies within the tentacle sheath, and during lophophore protrusion, the vestibular wall and parts of the tentacle sheath are turned outwards (Figs. 1c and 3a). In cross-sections, tentacles are more or less triangularly shaped and the tentacle

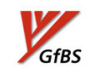


Fig. 1 Gross morphological overview of colonies of

Pherusella sp. a Frontal view of a mature ancestrula with a young bud on its proximo-lateral side. b Frontal view of a colony in a 4zooid stage with several larvae and embryos developing within one zooid. $\mathbf{c}$ Lateral view of a protruded lophophore. d Scanning electron microscopic image of a colony in a 3-zooid stage with the ancestrula on the right side. e Scanning electron microscopic image of the remains of the larval valves on the ancestrula. f Scanning electron microscopy image of the orifice with its characteristic rectangular shape. Abbreviations: $\mathrm{b}$ - bud, ca - cardia, cae - caecum, dp developing polypide, $\mathrm{eb}-$ embryo, es - esophagus, 1 lophophore, la - larva, mo mouth opening, or - orifice, $t$ tentacle, ph - pharynx, py pylorus, rlv - remain of larval valves, ts - tentacle sheath, vw vestibular wall
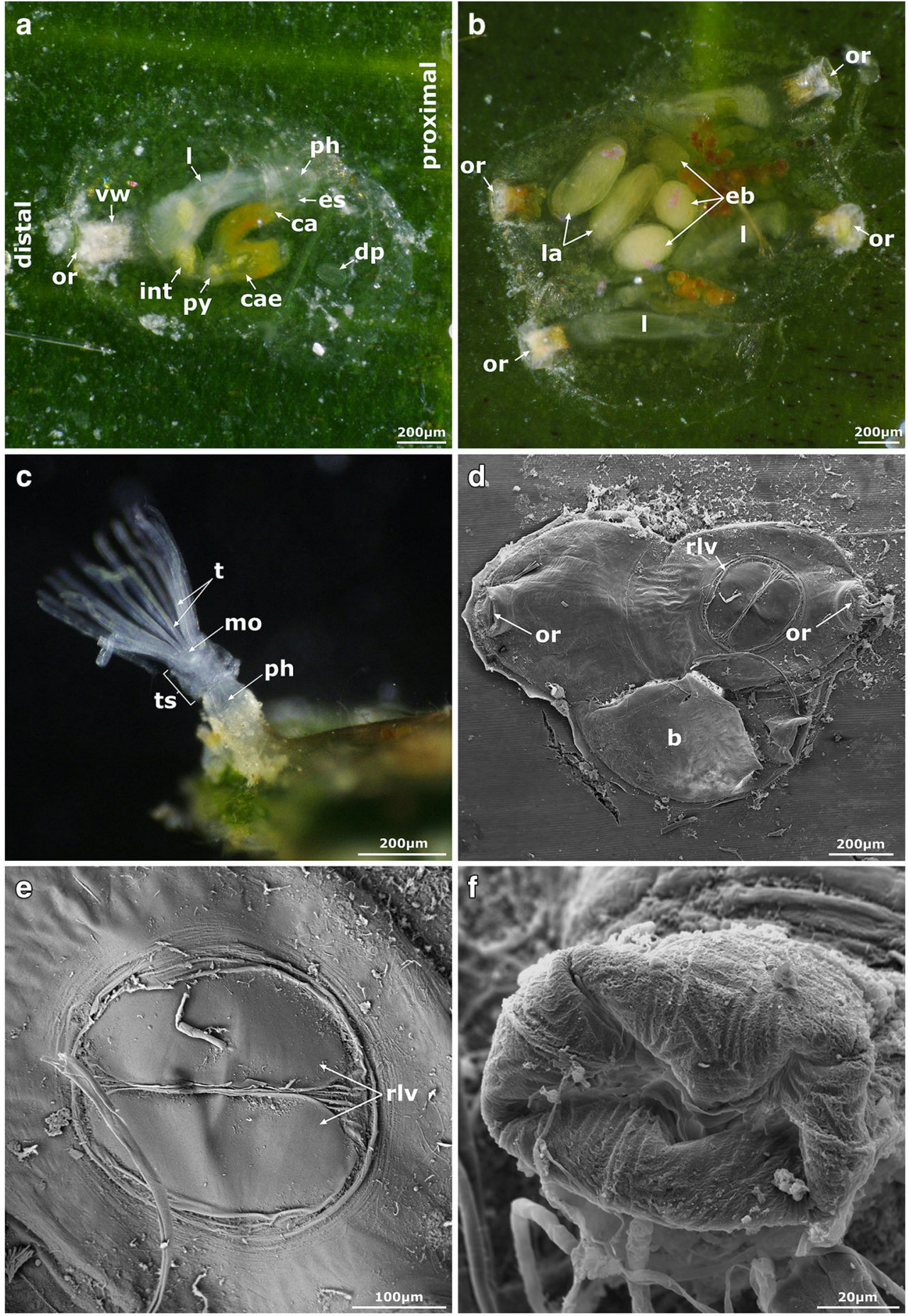

coelom proceeds throughout the entire length of the tentacles. The frontal side is covered by short frontal cilia. Longer lateral cilia are located on the lateral wall of the tentacles. Laterofrontal cilia are few in number and were encountered at the edges of the frontal side with a similar length as the lateral cilia, whereas the abfrontal side appears unciliated (Figs. 1c and $3 \mathrm{a}, \mathrm{b})$. The digestive tract is separated in three distinct sections: foregut, midgut, and hindgut. The foregut begins with a circular mouth opening at the lophophoral base and is followed proximally by a prominent and muscular pharynx. The first part of the pharynx has a pronounced ciliation until it bends and continues at the esophagus, which is less prominent than the pharynx. The foregut continues into the first part of the midgut, the tubular cardia, followed by a distinct caecum with a large lumen where food particles circulate (Supplementary video 1). The pylorus marks the end of the 
Fig. 2 Colony formation in Pherusella sp. Note the proximolateral budding pattern which leads to the establishment of two rows of zooids opposing each other with their proximo-lateral sides. On the left side are light microscopic pictures with the corresponding schematic representation on the right side. a Foundation of a colony with a mature ancestrula and a young developing bud on its left side. $\mathbf{b}$ Colony in a 2-zooid stage with two budding loci. c Colony in 4zooid stage. Colony already started with the production of larvae and embryos. d Colony in a 6-zooid stage. The arrangement into two series of zooids is now evident

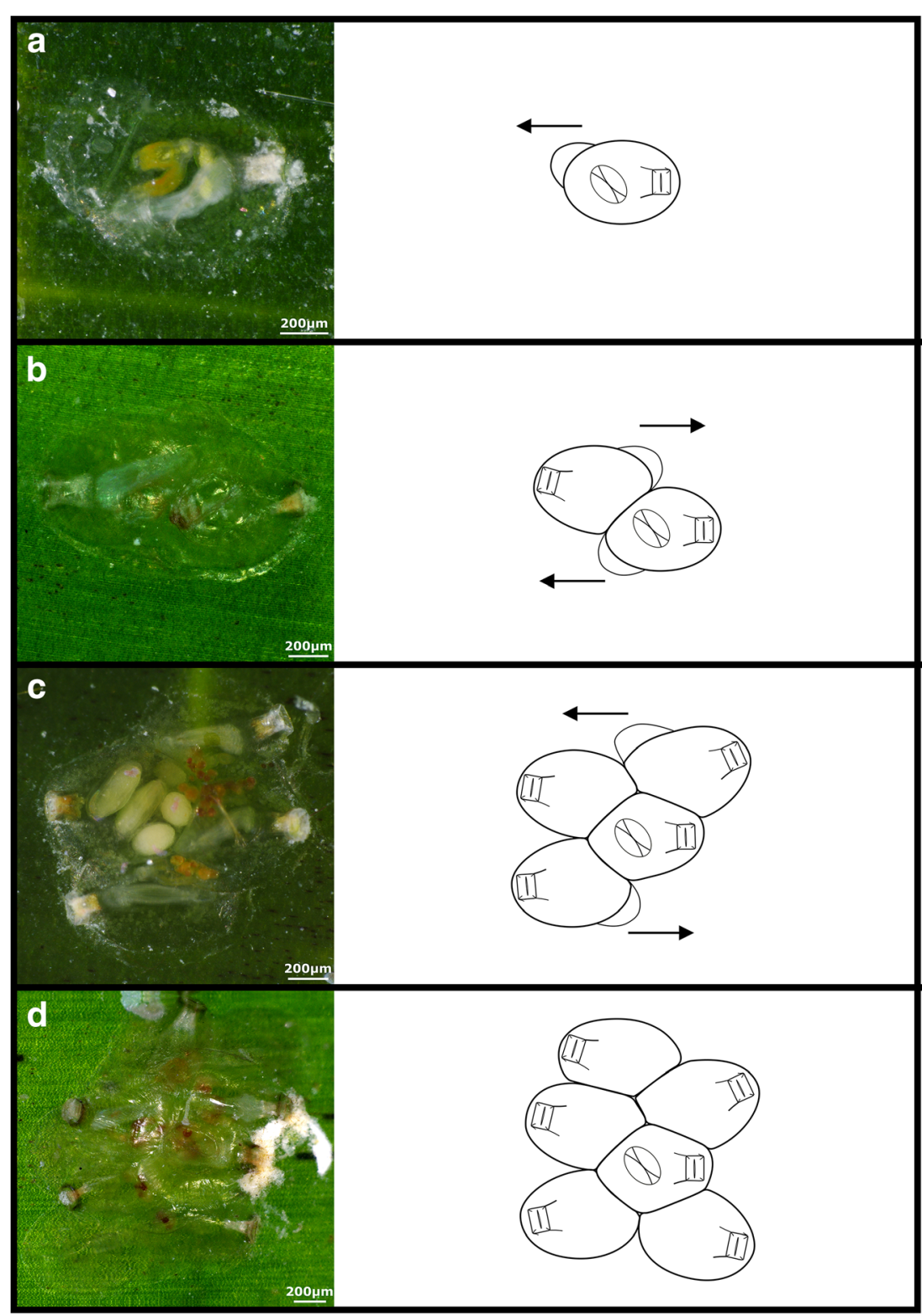

midgut and shows prominent ciliation. The hindgut includes the intestine and the anus. When the polypide is retracted, the intestine continues toward the tentacle sheath where the anus marks the end of the digestive tract by entering the atrium close to the diaphragmatic sphincter (Figs. 1a, 2d, and 4a).

In the proximal body wall, two multiporous pore complexes were encountered where attachment with a neighboring zooid occurs. The number of pore complexes within the lateral body walls seems to be inconsistent. These pore complexes usually feature three pores or perforations of about $1 \mu \mathrm{m}$ in diameter each (Fig. 5). Through each interzooidal pore complex between zooids, one "special cell" (see Bobin 1977) passes to interconnect the neighboring zooids. Both ends of the special cells are swollen. The rosette-like-shaped pore complex is formed by limiting cells that encircle the special cells in both zooids and shows distinct f-actin staining (Fig. $5 \mathrm{a}-\mathrm{d})$.

\section{Sexual reproduction and brooding}

Zooids containing larvae were encountered throughout the year (sampling predominantly from April to October) and may already form in colonies with three zooids (Figs. 1b and 2c), while in larger colonies, multiple zooids can contain embryos. Zooids that carry developing embryos degenerate almost their entire polypide in the process, except for the tentacle sheath, where brooding of the embryos takes place. A single zooid can develop up to five embryos at the same time (Figs. 1b and 2c). Once the larva has completed its development, it is released through the orifice of the mother zooid, a 
Fig. 3 Morphological overview of the lophophore, the frontal cystid wall, and the partitioning of the digestive system in adult Pherusella sp. a Histological semithin cross-section through a retracted lophophore surrounded by the tentacle sheath, bearing 21 tentacles. b Histological semithin cross-section through tentacles within the tentacle sheath. Note the different cilia. c Histological semithin longitudinal section through the cystid wall and the attached parietal muscle bundles. d Frontal view of a retracted polypide with its digestive system. Note the ciliation pattern of the digestive system particularly on the foregut, cardia, and pylorus. Staining against acetylated alpha-tubulin is indicated in green and cell nuclei in blue. Maximum intensity projection. Abbreviations: at atrium, bc - body cavity, ca cardia, cae-caecum, e- ectocyst, ecm - extracellular matrix, es esophagus, fci - frontal cilia, int intestine, lci - lateral cilia, ph pharynx, pm - parietal muscle, py - pylorus, $\mathrm{t}$ - tentacle, $\mathrm{tc}-$ tentacle coelom, tm- tentacle muscle, ts - tentacle sheath
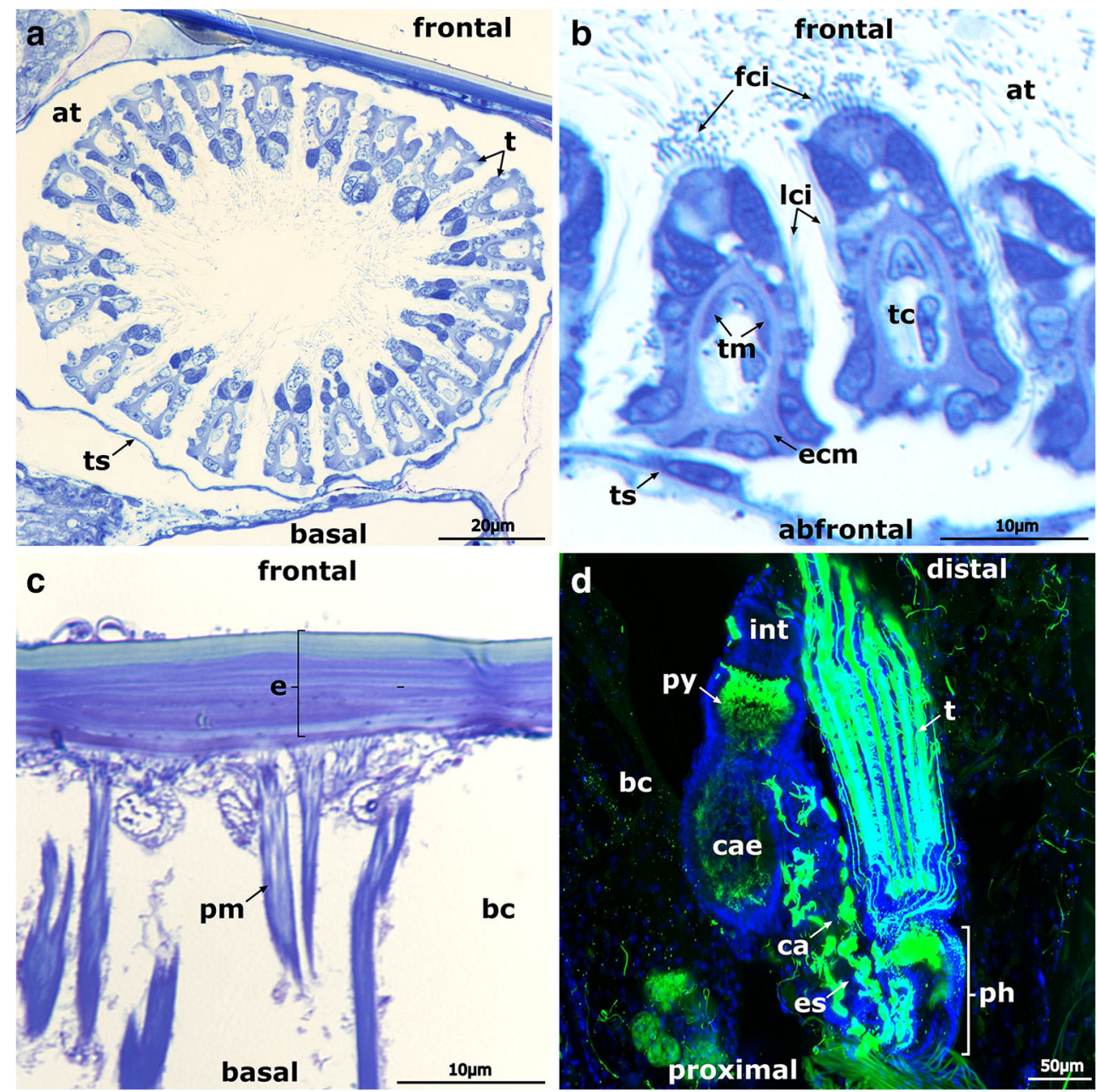

process which can take several days, involving repeated contractions of the vestibular wall. The released lecithotrophic pseudocyphonautes larva settles on suitable substrate within 2 days (Fig. 6, Supplementary video 1).

\section{Larval settlement and metamorphosis}

Metamorphosis from a settling larva into a mature autozooid with a functional polypide takes about 7 to 10 days. The larvae seem to prefer younger, not yet overgrown parts of the leaves close to the rhizome of Posidonia oceanica. If a suitable substrate is encountered, settlement is initiated and the larva spreads its two valves laterally with the oral side facing the substrate. Once the attachment to the substrate is established, metamorphosis starts (Fig. 6a). After 1 day, the larva has become a flat, disc-like preancestrula. Within 3 days, the cystid reaches its full size and the polypide anlage becomes evident as a small blister in the center of the zooid (Fig. 6b, c). The remains of the larval halves remain distinguishable and are located above the polypide anlage. The angle of these shells can be in parallel to the polypide anlage or various degrees up to $45^{\circ}$ (Fig. 6). The body cavity is filled with small granulate dots, which are remains of larval yolk and muscle anlagen of the parietal musculature (Fig. 6c, d). Polypide development takes three further days before the first tentacles of the lophophore as well as the digestive tract become visible (Fig. 6g, h). After 7 to 8 days, the orifice breaks through the frontal wall, thus enabling the lophophore to evert itself out of the cystid and the ancestrula can start filter feeding. During the following days, the peristomial tube elongates (Fig. 6h, i). The ancestrula starts to produce buds immediately after metamorphosis or may stay as single zooid for several days or even weeks until the first buds emerge.

\section{Colony growth pattern}

Colonies containing up to 16 zooids were observed with a regular colony pattern of two rows of zooids, which oppose each other with their proximo-lateral sides (Fig. 2d). One zooid, the ancestrula, emerges from a settling larva. When metamorphosis is completed, the formation of a bud on the proximal or proximo-lateral side takes place (Fig. 2a). The first bud then produces a second bud at the proximo-lateral side itself, which leads to the formation of two series of zooids (Fig. 
Fig. 4 Schematic representation of the muscular system of Pherusella sp. with retracted polypide. The musculature is indicated in red. a Frontal view. b Lateral view. Abbreviations: at atrium, c - coelom, ca - cardia, cae - caecum, db- duplicature band, ds - diaphragmatic sphincter, es - esophagus, $\mathrm{f}-$ funiculus, int - intestine, or orifice, $\mathrm{ph}$ - pharynx, pm parietal muscle, pv - parietovestibular muscle, py - pylorus, $\mathrm{rm}$ - retractor muscle, $\mathrm{t}$ - tentacle, ts - tentacle sheath, $v-$ vestibulum

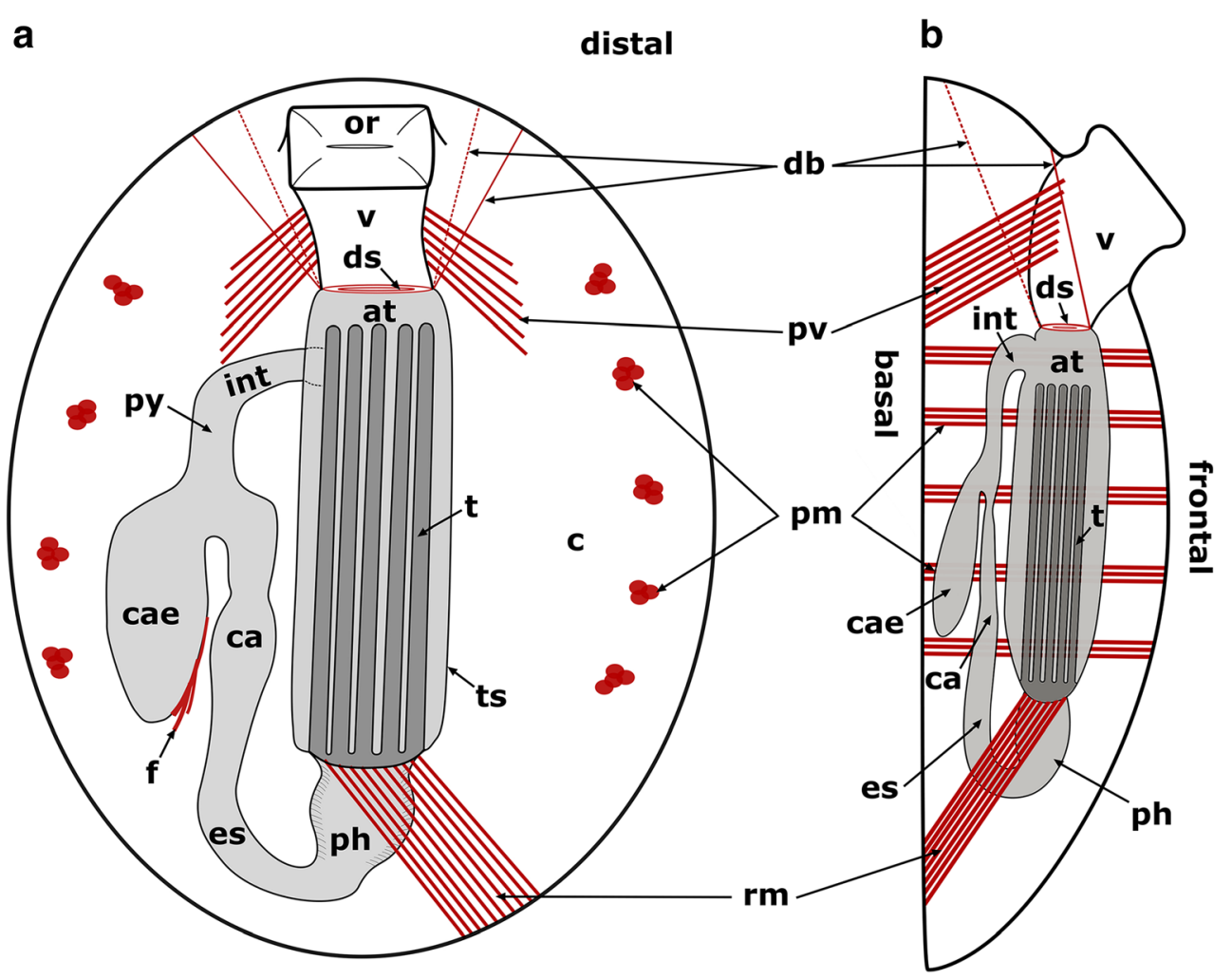

proximal 2c, d). At a colony size of more than 8 zooids, an additional row of zooids may emerge by budding on the distal sides. Colonies in a bilaminar or erect state were not observed (Fig. 2a-d).

\section{Autozooidal musculature}

\section{Body wall musculature}

In mature autozooids, a series of four to seven parietal muscle bundles cross the body cavity from the basal to the frontal wall on both lateral sides of the zooid. The parietal muscle bundles consist of several smooth muscle fibers (Figs. 4a, b and 7a). In developing zooids, the parietal muscles are the first muscles to develop and the first to start degenerating in degrading zooids (Fig. 7b, c).

\section{Apertural musculature}

The vestibular wall is everted when the lophophore is protruded and invaginated when the lophophore is retracted into the cystid (Fig. 1a, c). A single set of prominent parieto-vestibular muscles of smooth appearance runs from the basal wall in distal direction to insert on both lateral sides of the vestibular wall. The vestibular wall itself comprises a delicate mesh of circular muscle fibers. Six duplicature bands proceed from the distal region of the tentacle sheath to the distal body wall. One pair of the duplicature bands runs basally, while the second pair runs frontally of the parieto-vestibular musculature (Fig. 4). The third and last pair is broader and extends from the frontal side of the tentacle sheath distally (Fig. 8b). The tentacle sheath comprises fine and smooth longitudinal fibers, which run over the entire length of the tentacle sheath from proximal to the distalmost point. The longitudinal muscle fibers from the sheath extend into each duplicature band. The most proximal part of the vestibulum marks the beginning of the tentacle sheath, where a diaphragm with a diaphragmatic sphincter enables closure of the atrium-vestibulum border. Separate parieto-diaphragmatic muscles are missing (Figs. $4 a, b ; 7 a$; and 8b, c).

\section{Lophophoral musculature}

The lophophoral base is circular and comprises four different muscle sets. At the proximal end of the lophophore, buccal dilatators extend from the pharynx to the base of each tentacle. On the anal side of the lophophore where the cerebral ganglion is situated, two tentacles lack buccal dilatators. However, two buccal dilatator-like muscles originate proximally from the ganglion to form a clasp-like structure around the cerebral ganglion (Fig. 9a). Distally of the buccal dilatators the frontal lophophoral base muscle encircles the lophophoral base. Between the lophophoral base and the tentacle muscles, abfrontal longitudinal lophophoral base muscles extend about $25 \mu \mathrm{m}$ distally until the "v-shaped" muscles. The "v-shaped" 
Fig. 5 Communication pore complex in Pherusella sp. a Volume rendering based on a semithin section series showing a pore complex of the proximal body wall. b Histological semithin section through two adjacent zooids along the longitudinal axis, toluidine blue staining. Special cell runs through minute pore within the ectocyst of two adjacent zooids. c $+\mathbf{d}$ Frontal view of the cystid wall between two adjacent zooids. Special cell passes through the pores and connect two zooids. Surrounding cells creating a rosette-shaped complex. F-actin elements indicated in orange and cell nuclei in blue. Maximum intensity projection (c) and volume rendering $(\mathbf{d})$. Abbreviations: bc - body cavity, e - ectocyst, lc - limiting cell, $\mathrm{p}$ pore, $\mathrm{rm}$ - retractor muscle, $\mathrm{sc}-$ special cell
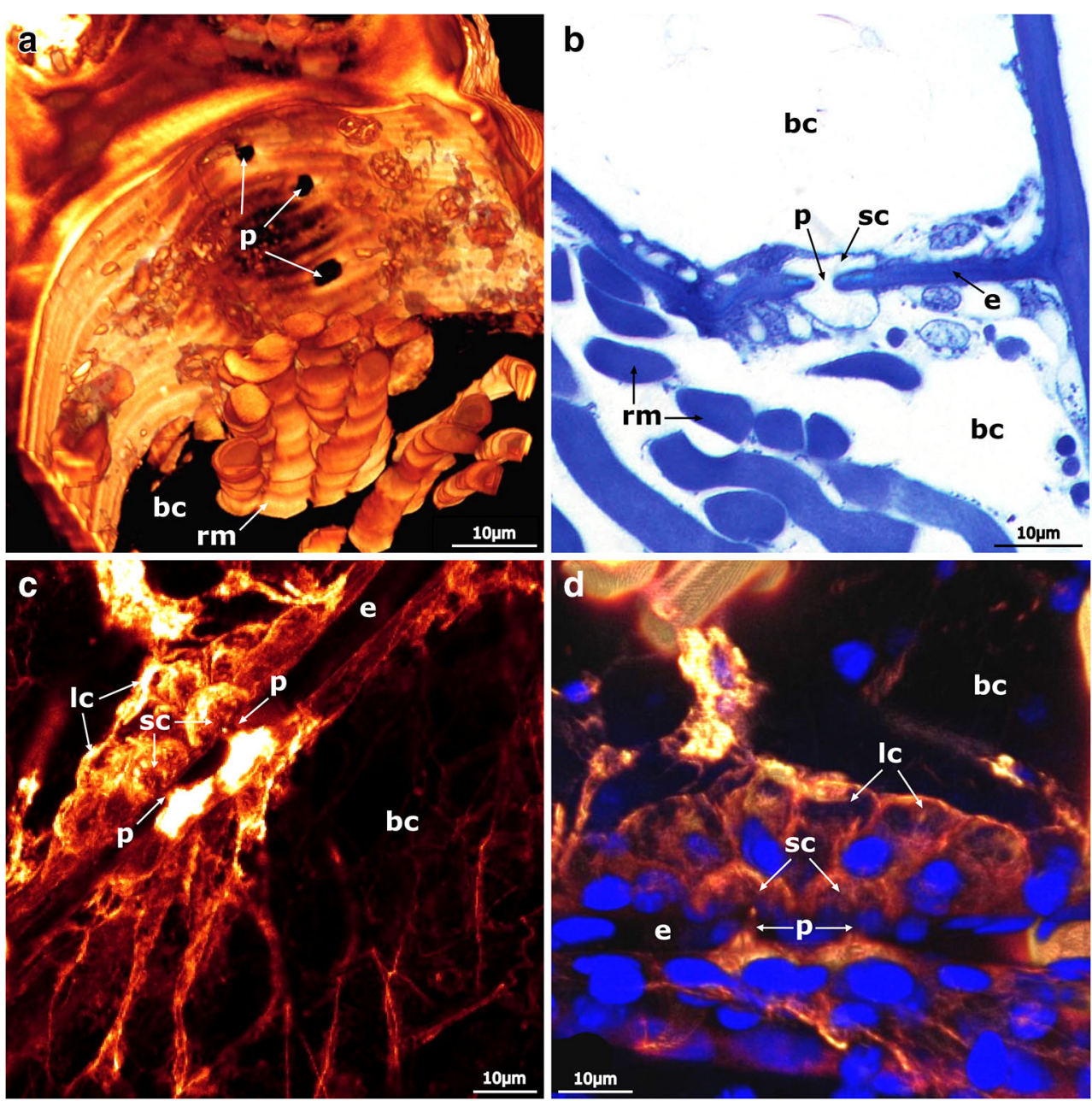

muscle has f-actin-rich elements which create a "v-shaped"like structure (Fig. 9a, b). Distally, a pair of longitudinal muscle bundles is present in each tentacle and proceeds until the distalmost part of the tentacles on both the frontal and abfrontal sides. The longitudinal tentacle muscles seem to have a striated appearance (Fig. 9a).

\section{Digestive tract musculature}

The pharynx comprises dense and cross-striated ring musculature, which becomes less prominent in the adjacent esophagus (Figs. 7a and 9a-c). The esophagus possesses smooth and less prominent ring musculature as well as few longitudinal muscle fibers that proceed toward the midgut (Fig. 9c, e). The esophagus ends in a tubular cardia with a similar musculature as the esophagus. The caecum comprises a fine and rather loose network of smooth ring and a few longitudinal muscle fibers. It continues into a pronounced pylorus with rather delicate f-actin filaments (Fig. 9e). At the transition from the cardia to the caecum, a funicular muscle emanates from the lining of the digestive tract toward the body wall (Figs. 4a and 9e). The hindgut comprises the intestine with distinct longitudinal muscles that proceed from the end of the pylorus toward the anus (Figs. 7a and 9c, e). The anus marks the end of the digestive tract (Fig. 4).

\section{Retractor musculature}

The prominent retractor muscle attaches at the entire lophophoral base and enables a rapid retraction of the polypide into the cystid. At the level where the esophagus bends and proceeds toward the caecum, the retractor muscle attaches more proximally at the pharynx. The retractor muscle continues to the most proximal part of the zooid and attaches to the lateral and basal wall (Figs. 4a, b and 7a). The retractor muscle has an irregular appearance of combined smooth and cross-striated muscle fibers (Fig. 9a, d).

\section{Autozooidal nervous system}

\section{Cerebral ganglion}

The cerebral ganglion is situated at the anal side of the lophophoral base as the center of the nervous system (Figs. 10, 11, and 12a-c). The proximal part of the 

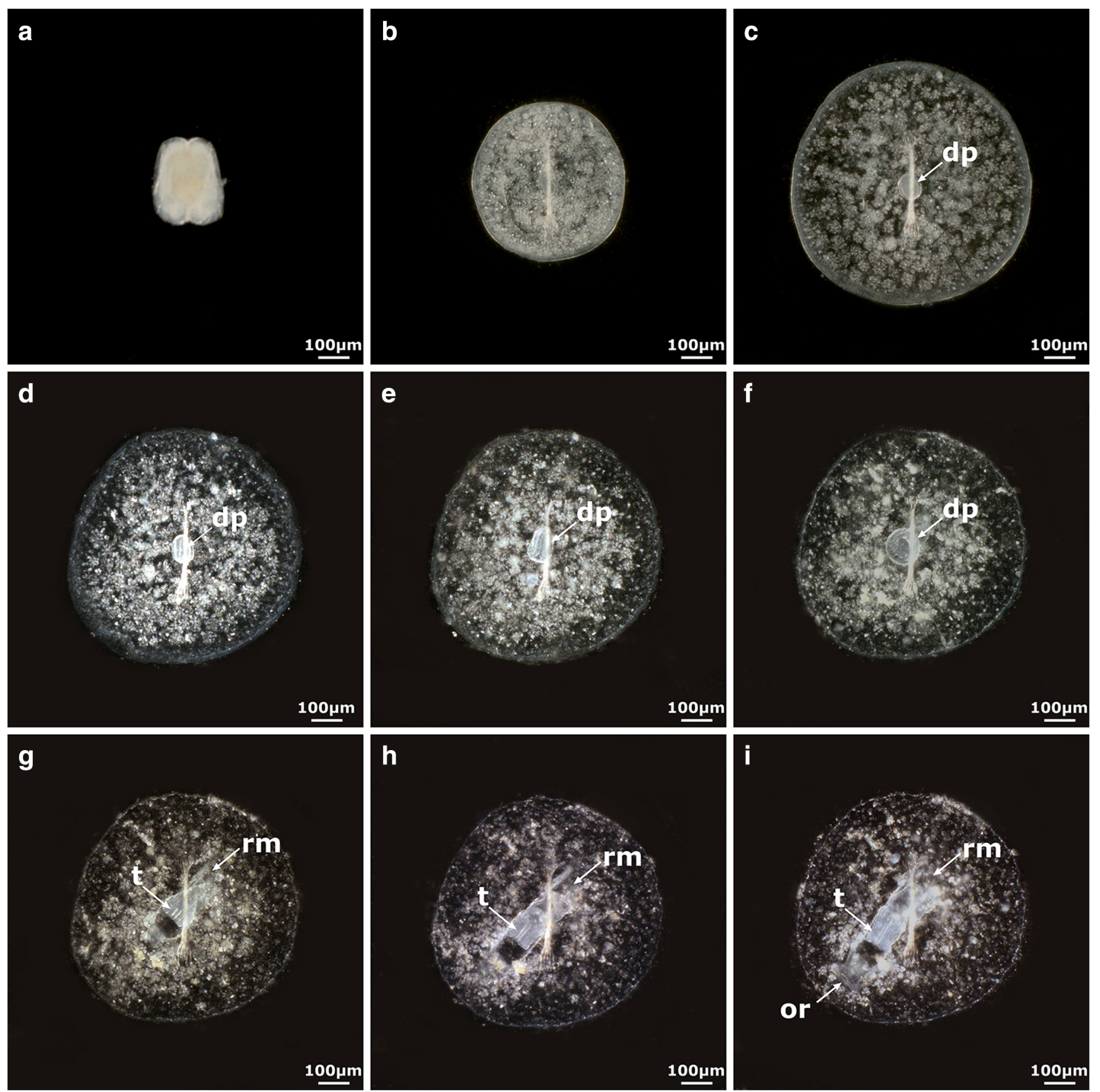

Fig. 6 Metamorphosis of Pherusella sp. from a settling pseudocyphonautes larva into an ancestrula. Frontal view of the same individual which settled on a coverslip. Each figure represents a time difference of $24 \mathrm{~h}$. a, b Establishment of the preancestrula with the larval valves remaining on the frontal wall of the ancestrula. c The cystid reached its final size and the developing polypide becomes

evident as well as parietal muscle anlagen which are dispersed together with the remains of larval yolk, throughout the body cavity (granulate dots). $\mathbf{d}-\mathbf{f}$ Stages of polypide bud differentiation. $\mathbf{g}$, h Retractor muscle becomes evident. i Aperture breaks through cystid and the polypide becomes functional. Abbreviations: $\mathrm{dp}-$ developing polypide, or orifice, $\mathrm{rm}-$ retractor muscle, $\mathrm{t}-$ tentacle

cerebral ganglion shows a distinct serotonin-like immunoreactive (lir) signal as well as two lateral lobe-like elongations in proximal direction (Fig. 12a-c). At the latero-distal part of the cerebral ganglion, the circumoral nerve ring emanates to encircle the mouth opening at the lophophoral base (Figs. 10a, 11, and 12). From the lateral sides of the cerebral ganglion, one "direct" tentacle sheath nerve and one "indirect" trifid nerve extend to innervate the tentacle sheath and distal parts of the peripheral nervous system (Figs. 11and 12). At the proximal margin, the cerebral ganglion gives rise to one 
Fig. 7 Autozooidal musculature and formation and degeneration of the parietal musculature of Pherusella sp. with retracted polypide. a Overview of autozooidal musculature from the basal side. Volume rendering. b Musculature of a degenerating zooid from the basal side. Volume rendering. c Developing parietal musculature in a young bud. Musculature is indicated in orange, cell nuclei in blue. Maximum intensity projection. Abbreviations: ap - aperture, $\mathrm{db}$ duplicature band, ds diaphragmatic sphincter, es esophagus, int - intestine, mo mouth opening, $\mathrm{rm}$ - retractor muscle, tm - tentacle muscle, $\mathrm{ph}$ pharynx, pm - parietal muscle, pv - parieto-vestibular muscle, py pylorus, v- vestibulum
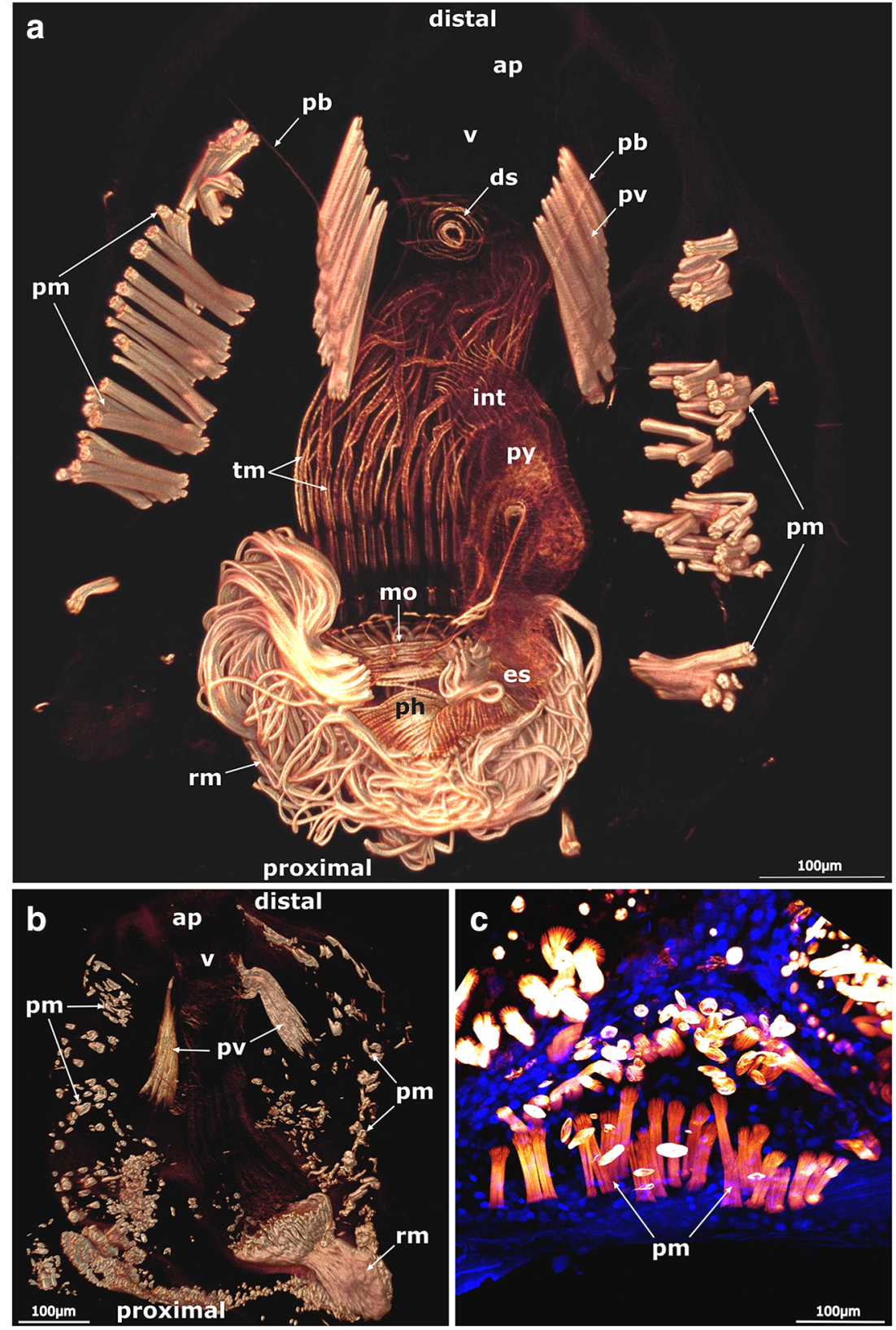

medio-visceral neurite bundle and a pair of mediolateral visceral neurite bundles (Figs. 11and 12a).

\section{Lophophore and tentacle innervation}

The base of the lophophore is innervated by the circum-oral nerve ring, which originates from the cerebral ganglion. The circum-oral nerve ring is a continuous ring that is closed on the oral side (Figs. 10a, 11b, and 12a, c). Each tentacle is innervated by a set of four basiepithelial neurite bundles that proceed distally along the longitudinal axis of each tentacle. From the circum-oral nerve ring, two distinct neurite bundles emerge to innervate each tentacle. The first one emanates directly from the circum-oral nerve ring and forms the medio- frontal neurite bundle which proceeds distally to the frontal side of the tentacle (Figs. 10 and 13a, b). The second bundle always emerges from an intertentacular position on the circum-oral nerve ring and proceeds distally toward the lophophoral base where it bifurcates. One branch extends into the median plane of each neighboring tentacle and forms the abfrontal neurite bundle that proceeds distally along the abfrontal side of the tentacle. The second branch extends intertentacularly and bifurcates again to extend as the paired latero-frontal neurite bundles (Figs. 10 and 13a, b). Each of the two latero-frontal neurite bundles proceeds toward the latero-frontal side of two neighboring tentacles. Consequently, the set of two latero-frontal neurite bundles within one tentacle emerges from two intertentacular 
Fig. 8 Apertural area and its musculature in a retracted polypide of an adult Pherusella sp. a Lateral view of the distal zooid part using a histological semithin longitudinal section. Toluidine blue staining. $\mathbf{b}+\mathbf{c}$ Frontal view of the musculature associated with the aperture area. Maximum intensity projection (b) and volume rendering (c). Note the muscle fibers in the third duplicature band are indicated by asterisk (*). Abbreviations: a anus, at - atrium, bc - body cavity, co - collar, db duplicature band, ds diaphragmatic sphincter, or orificium, pm - parietal muscle, $\mathrm{pv}$ - parieto-vestibular muscle, $\mathrm{t}$ tentacle, tm - tentacle muscle, ts tentacle sheath, $\mathrm{v}$ - vestibulum, $\mathrm{vw}-$ vestibular wall

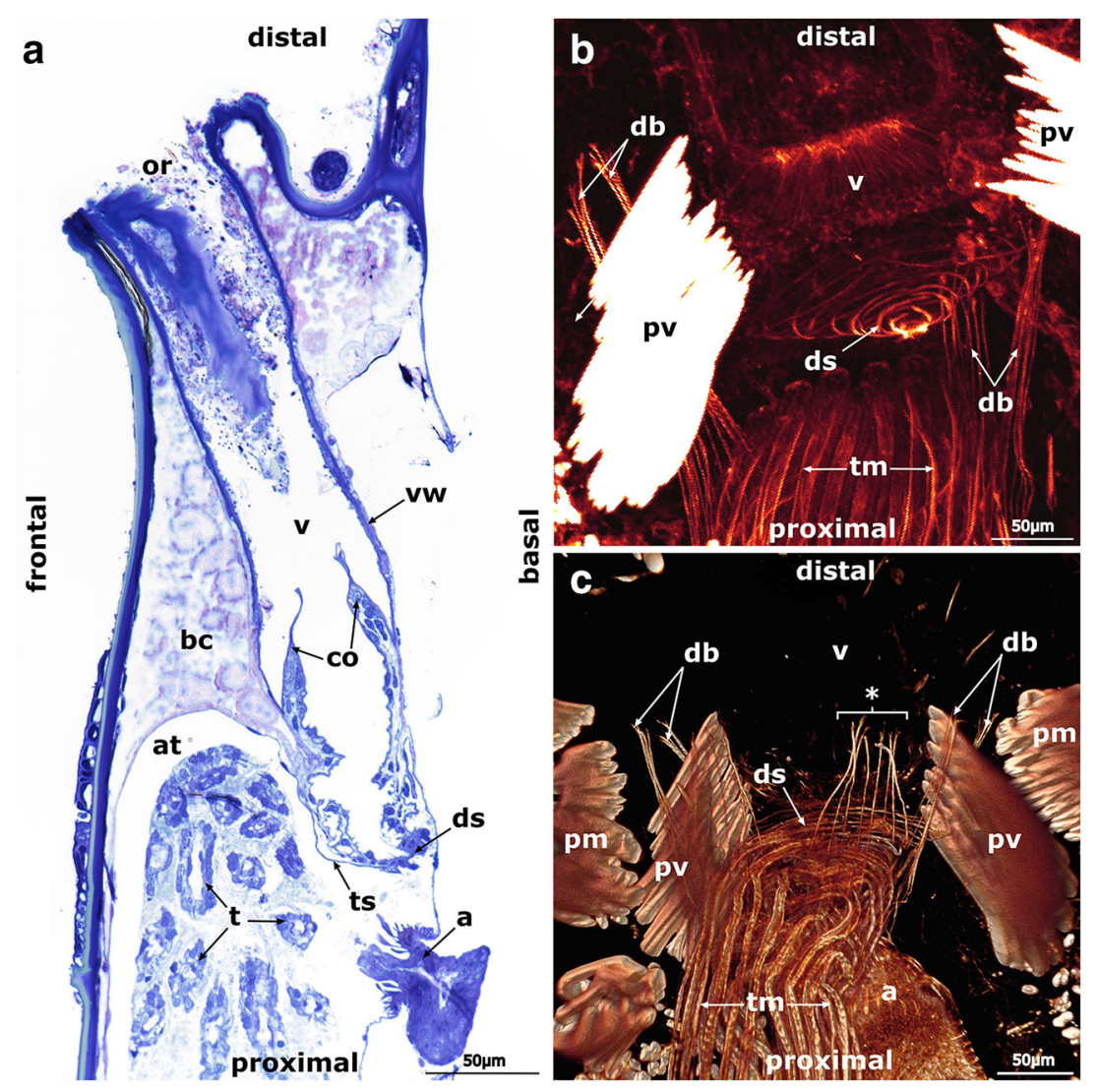

bifurcations (Figs. 10 and 13a, b). The situation of the tentacle innervation is different at the side of the cerebral ganglion. Here, two neurite bundles originate laterally of the cerebral ganglion to branch as intertentacular fork distally of the cerebral ganglion. At this particular intertentacular fork, four neurite bundles emerge, two abfrontal and two latero-frontal neurite bundles, which innervate the two tentacles adjacent to the intertentacular fork (Fig. 10a).

Within the intertentacular pits, perikarya are located and show a distinct serotonin-lir signal. The number of intertentacular pits is usually 17-19 and correlates with the tentacle number (Figs. $11 \mathrm{~b}$ and 12b, c).

\section{Tentacle sheath innervation}

The tentacle sheath is innervated by two sets of neurite bundles that originate at the disto-lateral or proximo-lateral side of the ganglion. The proximo-lateral trifid neurite bundles proceed on both lateral sides of the cerebral ganglion in lateral direction until they trifurcate (Figs. 10 and 11a, b). While two of the branches proceed in proximal and lateral direction where they innervate gut and retractor muscle, respectively, the remaining branch continues in the distal direction as tentacle sheath neurite bundle and innervates the tentacle sheath. The second set of neurite bundles originates on the distolateral side of the cerebral ganglion as direct tentacle sheath neurite bundle and proceeds distally. The two sets of tentacle sheath neurite bundles merge and continue as compound tentacle sheath neurite bundle on both lateral sides of the tentacle sheath toward the distalmost part where they extend to the innervation of the aperture and the parietal area (Figs. 11a, b; 12a, b; and 13c). A tentacle sheath ring neurite bundle has a distinctive serotonin-lir signal and encircles the tentacle sheath at the level where the compound tentacle sheath neurite bundle originates (Figs. $11 \mathrm{~b}$ and $12 \mathrm{~b}, \mathrm{c}$ ).

\section{Visceral innervation}

The foregut, i.e., pharynx and esophagus, is innervated by five neurite bundles, which originate from the cerebral ganglion to proceed in proximal direction along the anal side of the foregut. Three of them emerge directly from the proximal part of the cerebral ganglion: one prominent medio-visceral neurite bundle and two lateral and more delicate medio-lateral visceral neurite bundles. The three neurite bundles run in parallel to each other presumably until the cardiac valve at the end of the esophagus, but the innervation site was not resolved in detail. Two latero-visceral neurite bundles proceed along the lateral margin of the foregut. They emerge from the proximal branch of the trifid neurite bundle on both lateral sides (Figs. 11a, b and $12 \mathrm{a}, \mathrm{b})$. 
Fig. 9 Myoanatomy of a retracted polypide of an adult Pherusella sp. a Anal view of the lophophoral base. Volume rendering. Note the two buccal dilatators on a more proximal position, indicated by asterisk (*). b Oral view of retractor muscle and lophophoral base. Maximum intensity projection. c Distal view of musculature of the polypide. Maximum intensity projection. $\mathbf{d}$ Detailed view of retractor muscle shows f-actin fibers with a crossstriated pattern indicated by arrows. Maximum intensity projection. e Distal view of musculature of the polypide with particular focus on the longitudinal fibers proceeding along the esophagus and cardia. Volume rendering.

Abbreviations: al - abfrontal lophophoral base muscle, bd buccal dilatator, ca - cardia, cae caecum, es - esophagus, $\mathrm{f}-$ funiculus, $\mathrm{fl}$ - frontal lophophoral base muscle, int - intestine, mo mouth opening, ph - pharynx, phr - pharyngeal ring muscle, py pylorus, $\mathrm{rm}$ - retractor muscle, tm - tentacle muscle, vm - "v-

shaped" lophophoral base muscle
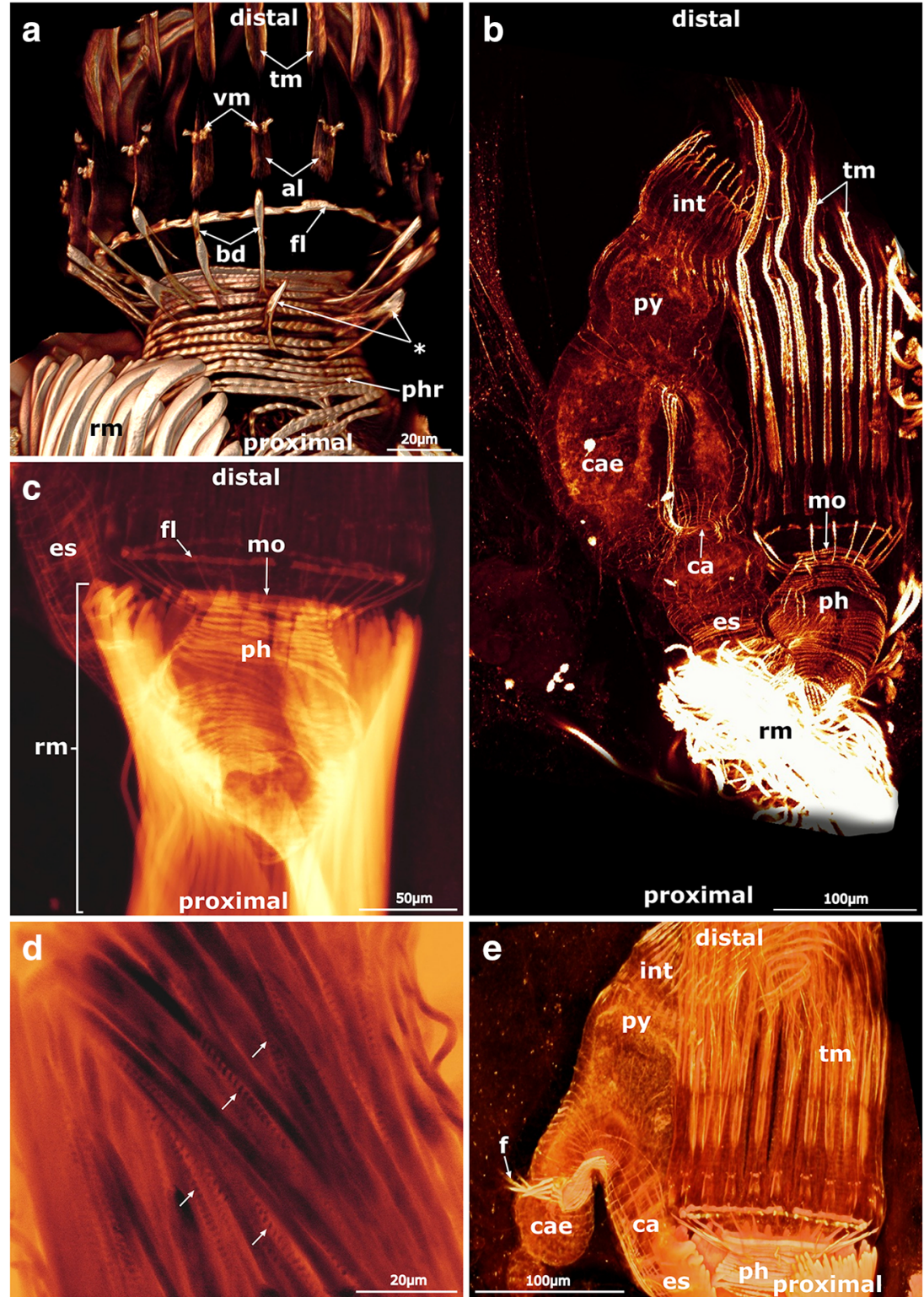

\section{Aperture and parietal innervation}

At the distal end of the tentacle sheath, the compound tentacle sheath neurite bundles proceed further distally along the frontal duplicature bands on both lateral sides of the vestibulum until they give rise to the parietal plexus, where it branches into several more delicate neurite bundles. From this ramification, single neurite bundles proceed in proximal direction toward each parietal muscle bundle and the parieto-vestibular musculature. Further in the distal direction, the main branch of the neurite bundle ramifies into more delicate neurite bundles and single nerve fibers to innervate the vestibular and basal wall as well as the disto-lateral cystid wall (Figs. 11a, b and 13c).

\section{Discussion}

\section{Autozooidal morphology}

Several ctenostome bryozoans show simple, oval-shaped zooids and are encrusters that form sheet-like colonies on various substrates. Alcyonidioideans (such as Pherusella) have such a growth form and most of its members show a similar shape and appearance of their zooids. In Pherusella brevituba, zooid shape changes in a similar succession as in Pherusella sp. from rather round in young colonies to irregularly rectangular and hexagonal in older and more compact colonies. The zooids in older colonies of $P$. tubulosa show a hexagonal shape as well, while information about younger colonies are unknown (Prouho 1892; Soule 1951, 1953). 

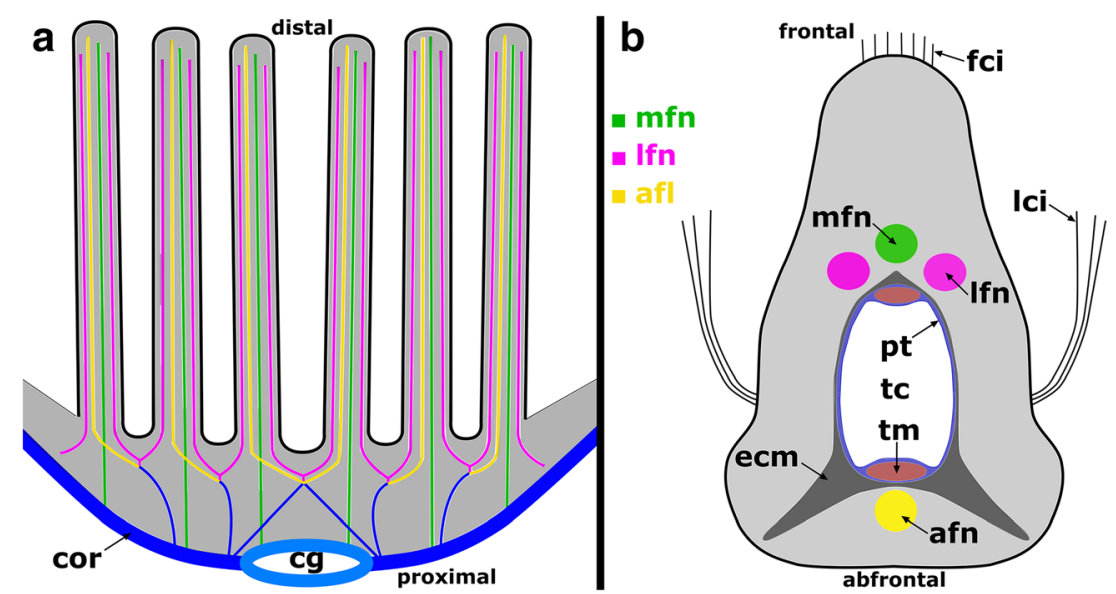

Fig. 10 Schematic representation of the tentacle innervation in Pherusella sp. Medio-frontal neurite bundle is indicated in green, latero-frontal neurite bundle in purple, and abfrontal neurite bundle in yellow. a longitudinal section through the lophophoral base and tentacles. b Cross-section through a tentacle. Abbreviations: afn -

abfrontal neurite bundle, cg - cerebral ganglion, cor - circum-oral ring neurite bundle, ecm - extracellular matrix, fci - frontal cilia, lci - lateral cilia, lfn - latero-frontal neurite bundle, $\mathrm{mfn}$ - medio-frontal neurite bundle, $\mathrm{pt}$ - peritoneum, tc - tentacle coelom, tm - tentacle muscle

Characteristic for the genus Pherusella is a peristome of variable length, which in the investigated Pherusella sp. is shorter than in other species (Prouho 1892; Soule 1951; D'Hondt 1983). An additional characteristic is the quadrangular aperture with four prominent folds of retracted zooids, which was described for P. brevituba and P. tubulosa (Prouho 1892; Soule 1951). The aperture of Pherusella sp. shows the same quadrangular shape which is considered an apomorphic character of the Pherusellidae and differs clearly from the radial aperture found in some closely related families (D’Hondt 1983; Hayward 1985; Schwaha 2019b).

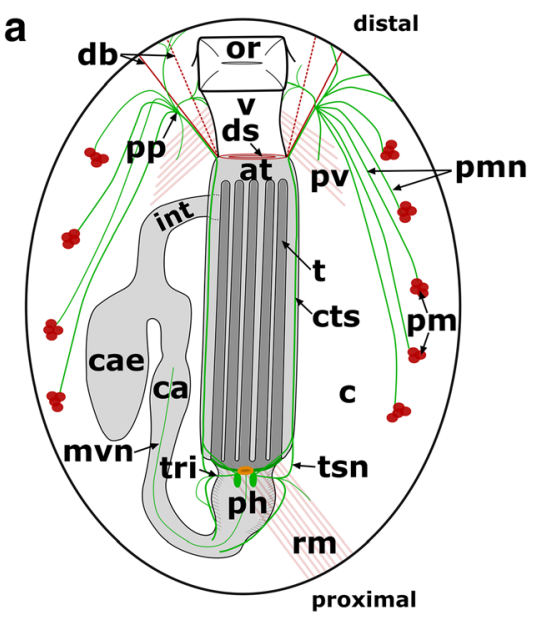

Fig. 11 Schematic representation of the peripheral nervous system in Pherusella sp. a Distal view of a retracted autozooid with nervous system indicated in green, musculature in red, and the polypide in gray. b Detailed overview of the peripheral nervous system in oral position. Circum-oral ring neurite bundle and the acetylated alpha-tubulin part of cerebral ganglion is indicated in green, serotonin-lir nervous system in orange, and the periphery in black. Abbreviations: at - atrium, c coelom, ca - cardia, cae - caecum, cg - cerebral ganglion, cor circum-oral ring neurite bundle, cts - compound tentacle sheath neurite

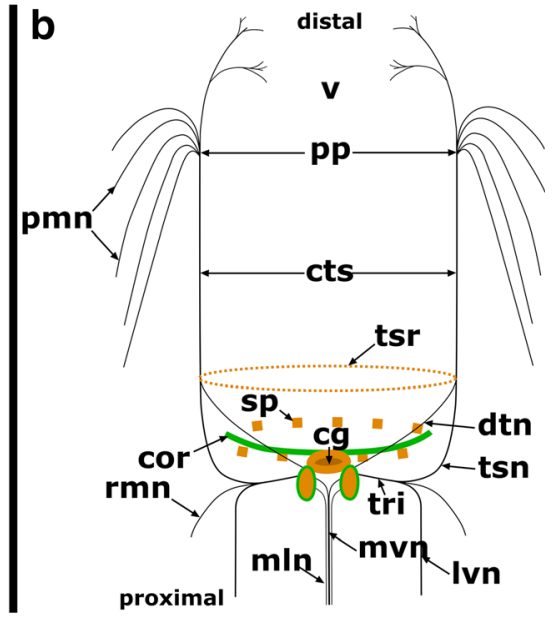

bundle, $\mathrm{db}$ - duplicature band, ds - diaphragmatic sphincter, dsn - direct tentacle sheath neurite bundle, es - esophagus, lvn - latero-visceral neurite bundle, mln - medio-lateral visceral neurite bundle, mvn medio-visceral neurite bundle, or - orifice, $\mathrm{ph}$ - pharynx, $\mathrm{pm}$ - parietal muscle, pmn - parietal muscle neurite bundle, $\mathrm{pp}$ - parietal plexus, pv parieto-vestibular muscle, $\mathrm{rm}$ - retractor muscle, rmn - retractor muscle neurite bundle, $\mathrm{sp}$ - serotonin-lir perikarya, $\mathrm{t}$ - tentacle, tri - trifid nerve, ts - tentacle sheath, tsn - tentacle sheath neurite bundle, tsr - tentacle sheath ring neurite bundle, $\mathrm{v}-$ vestibulum 

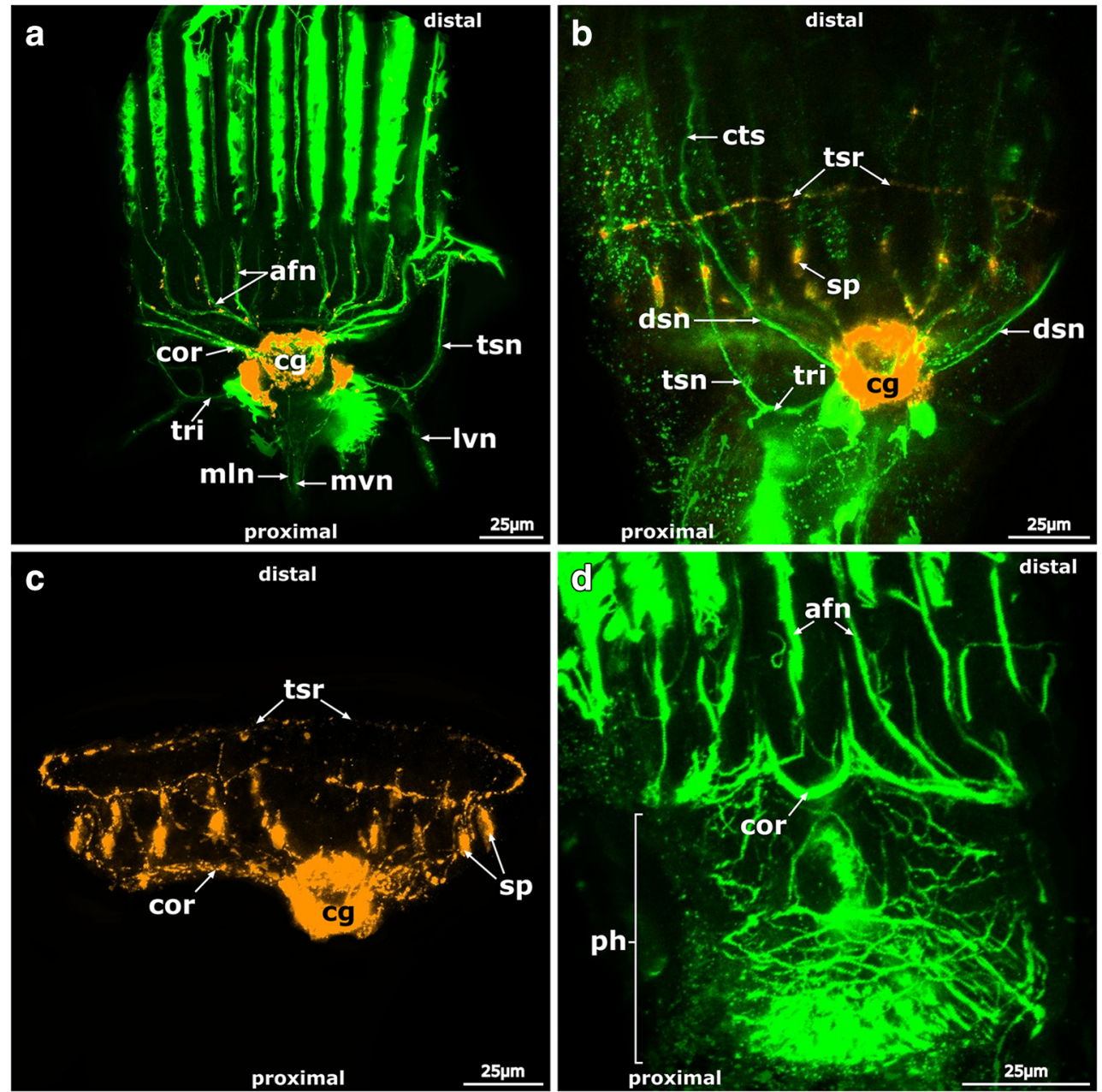

Fig. 12 Autozooidal nervous system of an adult Pherusella sp. Staining against acetylated alpha-tubulin is indicated in green and the serotonin-lir nervous system in orange. a Anal view of the lophophoral base with visceral neurite bundle proceeding further in proximal direction and tentacle sheath neurite bundle in distal direction. Prominent acetylated alpha-tubulin signal in the distal portion is induced by the cilia of the tentacles. Maximum intensity projection. b Anal view of the tentacle sheath innervation at the level of the lophophoral base and the compound tentacle sheath neurite bundle, and serotonin-lir perikarya in intertentacular pits. Maximum intensity projection. c Anal view of the

the genus show a variation of four to six (Prouho 1892; Soule 1951).

\section{Colonial growth pattern}

Within the genus Pherusella, a single zooid is formed from the ancestrula. At least in P. tubulosa and Pherusella sp., colonial growth and formation of the first bud begins after the ancestrula has completed its development into a mature autozooid (Prouho 1892; Soule 1953). In contrast, the Pacific $P$. brevituba simultaneously develops several peripheral chambers around a maturing ancestrula that are considered forming zooids. However, it is not clear if these incipient zooids will develop to autozooids and contribute to colonial

serotonin-lir part of the nervous system within the lophophoral base. Volume rendering. d Oral view of the lophophoral base with a prominent plexus enveloping the pharynx. Maximum intensity projection. Abbreviations: afn - abfrontal neurite bundle, cg - cerebral ganglion, cor - circum-oral ring neurite bundle, cts - compound tentacle sheath neurite bundle, dsn - direct tentacle sheath neurite bundle, lvn latero-visceral neurite bundle, $\mathrm{mln}$ - medio-lateral visceral neurite, mvn medio-visceral neurite bundle, $\mathrm{ph}$ - pharynx, $\mathrm{sp}$ - serotonin-lir perikarya, tri - trifid neurite bundle, tsn - tentacle sheath neurite bundle, tsr tentacle sheath ring neurite bundle

growth or if new budding events lead to the formation of new zooids (Soule 1953). In P. tubulosa and in colonies of Pherusella sp. from Sicily (Chimenz Gusso et al. 2004), the same budding process was reported as observed in this study for Pherusella sp. The first bud occurs on the proximal or proximo-lateral cystid wall of a mature ancestrula. When development of the autozooid is completed, it starts to produce the next bud on its proximal or proximo-lateral cystid wall, which consequently leads to the formation of two rows of zooids opposing each other with their proximal sides (Prouho 1892; Chimenz Gusso et al. 2004). Again, the budding pattern differs significantly from that described for the Pacific $P$. brevituba. Here, the budding loci alternate between the lateral and distal side. In the 2-zooid stage, the zooids are 
Fig. 13 Tentacle innervation and peripheral nervous system of an adult Pherusella sp. a + b Oral view of the lophophoral base with four neurite bundles innervating each tentacle. Staining against acetylated alpha-tubulin. b Medio-frontal neurite bundle is indicated in green, latero-frontal neurite bundle in purple, and abfrontal neurite bundle in yellow. Maximum intensity projection. c Peripheral nervous system shows the distal part with the parietal plexus und parietal muscle innervation. Staining against acetylated alpha-tubulin is indicated in green, musculature is indicated in beige, and cell nuclei in blue. Volume rendering. Abbreviations: afn - abfrontal neurite bundle, ap - aperture, $\mathrm{cg}$ cerebral ganglion, cor - circumoral ring neurite bundle, cts compound tentacle sheath neurite bundle, lfn - latero-frontal neurite bundle, mfn - medio-frontal neurite bundle, int - intestine, pm - parietal muscle, pmn - parietal muscle neurite bundle, $\mathrm{pp}$ parietal plexus, pv - parietovestibular muscle, $\mathrm{rm}$ - retractor muscle, $\mathrm{t}$ - tentacle, $\mathrm{v}$ vestibulum
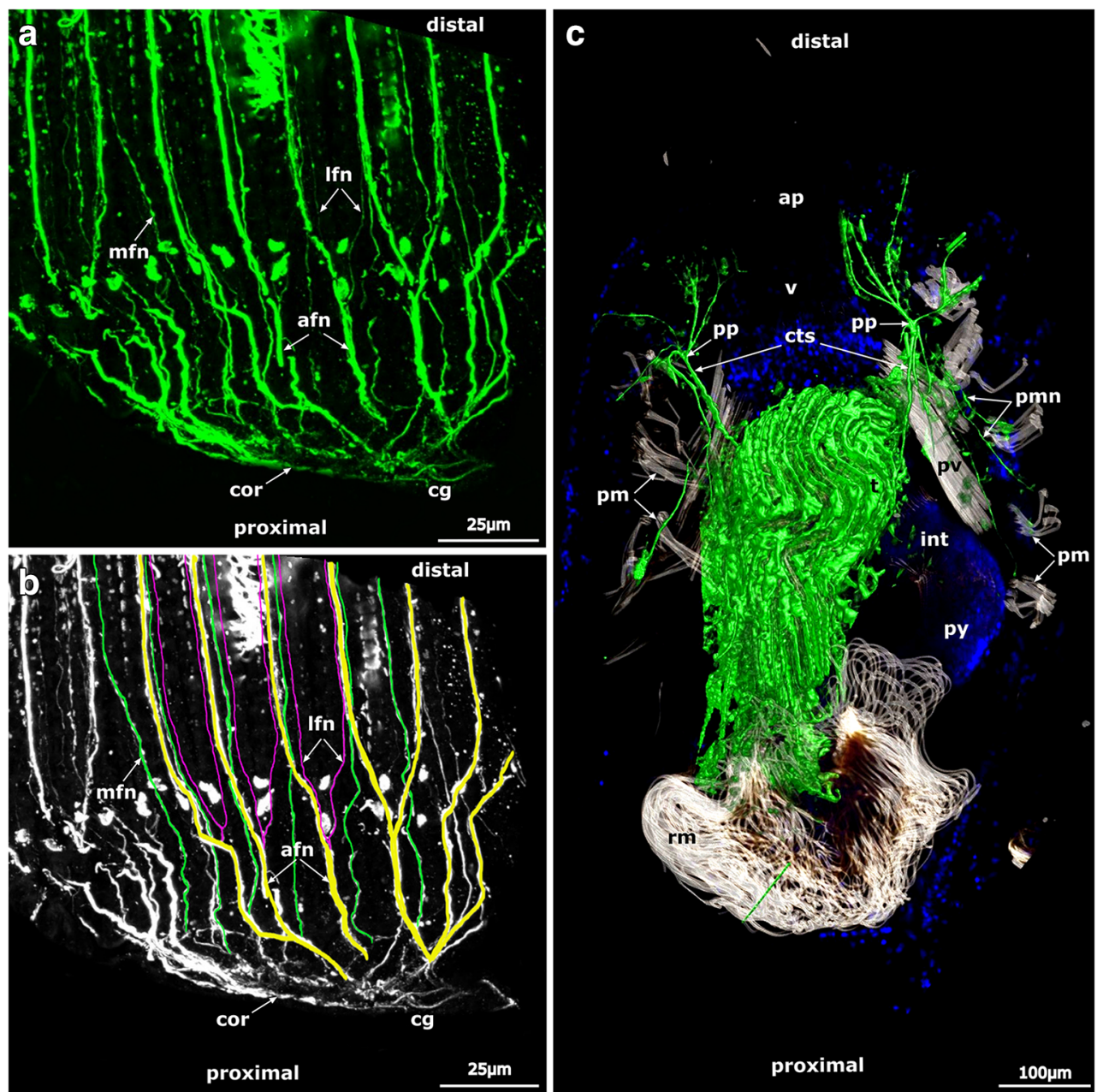

situated next to each other with their lateral sides, and in older colonies, the ancestrula is completely surrounded by zooids, instead of having a serial arrangement (Soule 1953). Remarkably, within gymnolaemates, budding events usually take place on the distal and lateral sides of zooids, which leads to a disto-lateral growth direction (Jebram 1973b). However, proximal budding events in Pherusella sp. were encountered until the 8-zooid stage, and only around the 10-zooid stage budding at the distal side is initiated, which consequently leads to the formation of additional rows of zooids and the colony enlarges along the proximo-distal axis.

Larger and older colonies of Pherusella tubulos $a$ and of the Pacific $P$. brevituba create erect branching structures, in contrast to only small encrusting colonies of Pherusella sp. The largest colony encountered in Pherusella sp. was in a 16-zooid stage, where specimens of Pherusella sp. from Sicily did not exceed the 8-zooid stage and were exclusively encrusting as well (Chimenz Gusso et al. 2004). The reason for smaller and exclusively encrusting colonies of Pherusella sp. can be many different environmental factors but most likely depends on the availability of suitable substrate. Suitable space on the leaves of Posidonia oceanica is limited owing to competition within the epiphytic community and the life span of the leaves itself. This becomes particularly evident during late spring and early summer when fast growing macroalgae overgrow large surface areas and animal abundance decreases, while in the winter months, animal abundance is the highest and algal cover is reduced (Ryland 1970; Prado et al. 2008). Consequently, colonies inhabiting $P$. oceanica do not reach a similar size to establish erect colony structures as do other members of the genus Pherusella growing on different substrates. The Pacific $P$. brevituba grows on the thallus of the giant kelp Macrocystis and $P$. tubulosa on various substrates such as different species of algae of the genus Cystoseira and on the rhizome of P. oceanica (Prouho 1892; Soule 1953; Riedl 1983).

\section{Sexual reproduction and brooding}

Most bryozoans are colonial hermaphrodites with male and female gametes either developing within different zooids of the colony, referred to as zooidal gonochorism, or within the same zooid known as zooidal hermaphroditism. Most gymnolaemates and cyclostomes have gonochoric zooids in 
their colonies (Reed 1991). In Pherusella sp., female zooids containing developing embryos are abundant, contrary to male gametes or testes, which have so far not been encountered. However, since colonies of Pherusella sp. reproduce throughout the year, male gametes are expected to occur, particularly as cross-fertilization seems to be the general pattern among bryozoans with no evidence of parthenogenesis (Ryland 1970; Reed 1991).

The perpetual detection of embryos throughout the year in colonies of Pherusella sp. leads to the assumption that there is neither seasonality in the reproductive cycle nor a distinct breeding season as observed for other bryozoans (Gordon 1970; Reed 1991; Ostrovsky 2013, 2019). Epiphytic bryozoans on algal blades or seagrass leaves show adaptations of their life cycles toward the host substrate. Colonies of these species are usually small with only a few zooids, since the longevity and size of colonies depend on the substrate stability and overgrowth rates by other epiphytic organisms. Species with short-lived colonies tend to produce embryos constantly throughout the year to ensure a fast recolonization of younger parts of the substrate. The number of zooids with developing embryos seem to correlate with the longevity and size of the colonies; thus, in smaller colonies with a short life span, most zooids can contain several embryos. Embryos also develop faster in these species to enhance a successful recolonization (Eggleston 1972). Pherusella sp. shows distinct adaptations of its life cycle toward a life on permanently altering substrates. Colonies do not exceed a 16-zooid stage, several zooids constantly produce embryos, and the settlement behavior of the larva shows a tendency toward the younger parts of the leaves. In contrast, no developing embryos were encountered in colonies of a similar size in the Pacific P. brevituba and the Mediterranean $P$. tubulosa. The latter shows a tendency to establish colonies on rather substantial and longer-lived substrates (Soule 1951, 1953; Riedl 1983).

Brooding in most common ctenostomes is within the tentacle sheath and rarely within the vestibulum (Ström 1977; Reed 1991; Ostrovsky 2013, 2019). Oogenesis is usually associated with degeneration of the polypide, and the maternal zooid undergoes a reorganization while brooding structures differentiate. This process was described in detail in Alcyonidium gelatinosum (Linnaeus, 1761) (Matricon 1963). The same succession of polypide degeneration and simultaneous development of up to five large and yolky embryos within the tentacle sheath was observed in Pherusella tubulosa (Prouho 1892; Zimmer and Woollacott 1977b). Thus, brooding and development of embryos in Pherusella sp. corresponds to the pattern observed in other alcyonidioideans.

The end of larval development in Pherusella sp. is apparent when cilia of the larva start beating. Then, the larva slowly moves distally toward the vestibulum and orifice. When disturbed, the larva can also be pulled back into the zooid as protective behavior. In many bryozoan species, larval release is induced by exposure to daylight (Reed 1987), but this seems to have no influence in inducing larval release in Pherusella sp.

Two major categories of larval types can be distinguished in gymnolaemate bryozoans: coronate and shelled larvae. The former are always lecithotrophic, and the latter either planktotrophic or lecithotrophic. Shelled planktotrophic larvae, referred to as cyphonautes larvae, possess a welldeveloped digestive system and have a long pelagic stage (Zimmer and Woollacott 1977a; Gruhl 2019). Due to the similarity with cyphonautes larvae in terms of morphology, shelled lecithotrophic larvae are called pseudocyphonautes and show only rudiments of a digestive system. They develop from large and yolky eggs and settle after a brief pelagic stage onto suitable substrate. The latter unique larval type was so far only reported in three ctenostome species, Flustrellidra hispida (Fabricius, 1780), Pherusella tubulosa and the Pacific P. brevituba, and now in Pherusella sp. (Prouho 1892; Soule 1953; Zimmer and Woollacott 1977a; Kvach et al. 2019). Since the pseudocyphonautes larva is unique for the genus Flustrellidra and Pherusella, which are closely related, it most likely represents a synapomorphic character for the two genera.

\section{Larval settlement and metamorphosis}

During settlement phase, the larva probes different substrates for settlement (Reed 1991). Experimental studies with several bryozoan species showed that bryozoan larvae have speciesspecific substrate preferences. Larvae of the ctenostome bryozoan Alcyonidium polyoum (Hassall, 1841) favor settlement on younger, less vegetated blades of a brown alga (Ryland 1959), similar to the preference of Pherusella sp. larvae to settle on the basal, younger parts of the leaves. This behavior leads to an increased lifespan of the future colony, especially on senescent substrate types, and reduces competition of space between various different sessile epiphytes (Reed 1991). Substrate-specific cues that induce the settlement process remain unknown, but microbial films or certain other epiphytes on substrates can encourage larval settlement (Brancato and Woollacott 1982; Reed 1991; Gruhl 2019). Larvae of Amathia gracilis (Leidy, 1855) start with an exploratory behavior when a suitable substrate is encountered by crawling over the substrate, probably by means of ciliary gliding. During this exploratory behavior, the oral hemisphere faces the substrate and the pyriform organ is pressed against it (Reed and Cloney 1982). Larval settlement initiates eversion of the internal sac which marks the beginning of metamorphosis (Zimmer and Woollacott 1977b; Reed and Cloney 1982). During larval settlement in Pherusella sp., the two larval valves spread laterally and the larva becomes a flat disc as reported for the Pacific P. brevituba (Soule 1953). 
Metamorphosis is organized into two phases in which the larva becomes completely reorganized by a sequence of morphogenetic movements (Nielsen 1971). The first phase leads to a solid attachment of the larva to the substrate and the formation of a preancestrula, a rapid process that lasts only a few minutes. In the second and longer phase, the preancestrula matures to a true zooid, the ancestrula. Histolysis of larval organs and histogenesis of adult organs lead to the establishment of a mature ancestrula within 1 to 6 days depending on the species (Nielsen 1971; Zimmer and Woollacott 1977b; Reed 1991). The transformation into an ancestrula might take several additional days (see also Nielsen 1971).

Before the polypide starts to develop and emerge, remains of larval yolk and anlagen of parietal musculature are dispersed throughout the entire preancestrula of Pherusella sp. The same developmental succession is present in several ctenostome bryozoans of an encrusting morphology such as Flustrellidra hispida and Alcyonidium gelatinosum (Jebram 1986). The development and origin of the polypide anlage starts already within the preancestrula and becomes evident in the onset of the second or third day of development. The polypide anlage in the preancestrula of $F$. hispida and A. gelatinosum is located in the future proximal part of the cystid, while the polypide anlage in Pherusella sp. is rather centrally located in the future ancestrula (Jebram 1986; Reed 1991). Pherusella sp. follows the general differentiation pattern into a functional polypide, which characterizes the second phase of metamorphosis. Tentacle buds emerge and elongate within several days, while synchronous differentiation of the digestive system into a u-shaped gut takes place. During tentacle elongation, the future position of the aperture shifts into the distal direction (Zimmer and Woollacott 1977b). Metamorphosis into the ancestrula is completed when it becomes a functional zooid. Therefore, the formation of the orifice for lophophore protrusion must be completed before the ancestrula can start filter feeding (Zimmer and Woollacott 1977b; Reed 1991).

Details of the histological procedures and reorganization during larval metamorphosis remain little studied (see Nielsen 1971; Reed 1991). Metamorphosis is usually termed catastrophic with most of the larval tissues degenerating and adult ones forming de novo (Reed 1991). There are only slight indications of incorporation of the larval gut into the adult polypide in the ctenostome Hislopia malayensis Annandale, 1916, which possesses cyphonautes larvae (see Schwaha et al. 2020 for a summary). Metamorphosis of pseudocyphonautes larvae has only been studied in Flustrellidra hispida, but dates back to 1890 by Prouho. With optimization of the settlement process, which occurred predominantly on cover slips in our experiments, the easy access and availability of larvae of Pherusella sp. allows for closer studies of metamorphosis in the future.

\section{Autozooidal musculature}

\section{Body wall musculature}

The paired parietal musculature plays an important role in the protrusion mechanism of the polypide in Gymnolaemata and is characteristic for this clade (Schwaha 2019a). In Pherusella sp., the number of parietal muscle bundles within one row seems to be inconsistent, since different numbers were encountered, or the bundles even formed one continuous row and not discreet bundles. Degeneration and regeneration processes of the polypide are well-known for many different bryozoans, but not for the parietal muscles. It has been reported that the parietal muscles remain unchanged within a zooid where the polypide undergoes regeneration (Gordon 1977). Since colonies of Pherusella sp. are short-lived, only the degeneration of polypides was observed with no signs of polypide recycling.

Another feature of gymnolaemates is communication pores with three different cells that form a rosette-shaped pore complex (Mukai et al. 1997; Schwaha et al. 2020). Cincture cells line the actual pores and reduce the diameter of the pore (Mukai et al. 1997; Schwaha 2019a). In Pherusella sp., no cincture cells were found associated with a pore, probably ultrastructural methods are required to resolve these in full detail. Special cells pass through the pore and connect two adjoining zooids. In some ctenostomes, several special cells run through one large pore (Bobin 1977), whereas in Pherusella sp., only one special cell passes through a much smaller pore. The limiting cells surround the pore complex laterally, which gives it the rosette-like appearance (Mukai et al. 1997). Special and limiting cell types can contain distinct f-actin filaments in Pherusella sp., whereas most other ctenostomes mostly have f-actin in special cells (see Schwaha and Wanninger 2018; Pröts et al. 2019).

\section{Apertural and tentacle sheath musculature}

Three different sets of aperture muscles are differentiable in bryozoans: (1) distally located muscle fibers referred to as parieto-vestibular and parieto-diaphragmatic muscles, (2) duplicature bands with some smooth muscle fibers, and (3) musculature of the vestibular wall (Schwaha and Wanninger 2018). The parieto-vestibular musculature is present in all investigated ctenostomes and constitutes the most prominent ones of those associated with the aperture. The situation in Pherusella sp. is similar to Hislopia malayensis, where parieto-vestibular muscles are bilaterally arranged on both sides of the vestibular wall and extend to the basal wall (Schwaha et al. 2011). In stolonial ctenostomes, the parietovestibular muscles run from the vestibular wall toward the lateral body walls instead (Schwaha and Wanninger 2018). 
Distinct muscle fibers lining the vestibular wall were reported for most investigated ctenostomes with a few species showing an orthogonal orientated grid of muscle fibers within the vestibular wall, such as $H$. malayensis, where additional diagonal muscle fibers are present in the basal part of the vestibular wall (Schwaha et al. 2011; Schwaha and Wanninger 2018). Pherusella sp. shows only a faint set of circular muscle fibers within the vestibular wall similar to other alcyonidioid genera. The latter only possess a pronounced orifical sphincter, which is not present in Pherusella sp. (Schwaha and Wanninger 2018).

The diaphragmatic sphincter is present in all bryozoans investigated so far. In most analyzed bryozoans, the parietodiaphragmatic muscles show a similar traverse as the parietovestibular ones and insert at the diaphragm (Schwaha et al. 2011). Parieto-diaphragmatic muscles in Pherusella sp. are missing, but similar to $H$. malayensis, the parieto-vestibular musculature attaches to the diaphragm (Schwaha et al. 2011).

A set of four duplicature bands seems to be the general arrangement in most ctenostome bryozoans with only a few species diverging from this pattern (Schwaha et al. 2020). In Pherusella sp., an additional pair of broader duplicature bands extends from the tentacle sheath to the frontal wall, next to the other frontal pair. Six duplicature bands have not been frequently found in many bryozoans so far (see Schwaha et al. 2020).

The tentacle sheath possesses only longitudinal muscle fibers in most myolaemate bryozoans (Schwaha 2019a). Only walkerioidean and victorellid ctenostomes show diagonal muscle fibers within the tentacle sheath, which probably is a synapomorphy of walkerioideans and Victorellidae (Schwaha and Wanninger 2018). Tentacle sheath musculature plays a crucial role in the brooding of embryos which can take place inside the tentacle sheath (Reed 1991; Ostrovsky 2013, 2019). Contraction of the longitudinal muscle fibers embedded in the tentacle sheath may contribute to the displacement process of the embryos toward the aperture before they can be released.

\section{Lophophoral musculature}

The lophophoral base of all investigated ctenostomes comprises three to four sets of muscles that differ in their size and shape (Schwaha 2019a; Schwaha and Wanninger 2018). Most gymnolaemates have smooth buccal dilatators with several ctenostomes possessing striated ones, but its functional significance is not clear. In Pherusella sp., two buccal dilators do not insert at the base of the corresponding tentacles but instead insert more proximally at the cerebral ganglion; consequently, the two tentacles have no buccal dilatators. A second pair of buccal dilatators in association with the cerebral ganglion has so far only been described for Hislopia malayensis (Schwaha et al. 2011). In Pherusella sp., a modification of the two buccal dilatators seems to have occurred which moved the dilatators further proximally, leaving the corresponding tentacles without buccal dilatators.

The frontal lophophoral base muscle forms a continuous ring muscle around the mouth opening at the base of the tentacles in Pherusella sp. and several other investigated species (Schwaha and Wanninger 2018). In cheilostomes, this muscle is discontinuous and termed basal transversal muscle (Gordon 1974; Schwaha et al. 2011), which is also shared by other ctenostomes including alcyonidioideans (Schwaha and Wanninger 2018). Consequently, the configuration of this muscle in ctenostomes is variable, even in closely related taxa. Abfrontal lophophoral base muscles are similar in all investigated gymnolaemates and differ only in length between species. Pherusella sp. is no exception in this case (Schwaha and Wanninger 2018).

The "v-shaped" muscles at the lophophoral base are present in all ctenostomes including Pherusella sp. where it is present as three separate f-actin-rich elements, two of which are located laterally and more distally, while the third one is located medio-proximally. The latter can also be absent or vestigial in several species (Schwaha and Wanninger 2018).

Tentacles of all bryozoans are supplied with two longitudinal muscle bands, one on the frontal and the second on the abfrontal side of each tentacle (Schwaha and Wanninger 2018). In Pherusella sp., these are smooth, whereas striation had been reported in some previous reports. In the ctenostome Cryptopolyzoon wilsoni (Dendy, 1889), only the abfrontal muscle bands are striated, whereas the frontal muscle bands are smooth (Schwaha and Wanninger 2018). Distal tips of tentacle are important in sperm dispersal in many bryozoans as they are released via pores at the tips of the two adneural tentacles (Silen 1966). In Pherusella sp., such structures were not observed.

\section{Digestive tract and retractor musculature}

The digestive tract musculature of Pherusella sp. is similar to all other investigated ctenostomes and does not show any distinct specializations: the foregut has prominent and cross-striated ring musculature with sparse longitudinal fibers in the esophagus. The midgut has few smooth circular and longitudinal fibers, followed by the hindgut showing longitudinal fibers (see Schwaha and Wanninger 2018; Schwaha 2019a).

In all investigated bryozoans, the retractor muscle attaches to the body wall and traverses the body cavity to insert at the lophophoral base. In Pherusella sp., fibers also insert at the pharynx and esophagus which leads to the formation of a gap on the basal side of the retractor muscle as reported for other gymnolaemates (Hyman 1959). 


\section{Autozooidal nervous system}

The general structure of the nervous system of Pherusella sp. is similar to other bryozoans. A cerebral ganglion and a circum-oral nerve ring $(\mathrm{CON})$ are located at the lophophoral base. From these structures, most neurite bundles emanate to innervate the remaining parts of the polypide, i.e., lophophore, digestive tract, and peripheral areas (Gruhl and Schwaha 2015; Schwaha 2019a).

\section{Lophophore and tentacle innervation}

Projections of the circum-oral nerve ring and the cerebral ganglion innervate each tentacle, with the majority of investigated gymnolaemates including the herein investigated Pherusella sp. showing a set of four subepidermal neurite bundles in each tentacle (see Gruhl and Schwaha 2015; Schwaha 2019a). The site of origin of the tentacle neurite bundles differs among species. In Pherusella sp., the medio-frontal neurite bundle branch off the circum-oral nerve ring or the cerebral ganglion at the base of each tentacle, and the remaining ones have an intertentacular origin, which has been reported for most gymnolaemates including ctenostomes (Gruhl and Schwaha 2015; Schwaha 2019a). At the anal side where the cerebral ganglion is situated, two instead of one abfrontal neurite bundles emerge from the intertentacular fork, similar to the situation in the ctenostome Hypophorella expansa Ehlers, 1876 (Pröts et al. 2019).

Between the base of each tentacle in Pherusella sp., intertentacular pits are present with perikarya that show a distinct serotonin-lir signal, as reported for other gymnolaemates (Schwaha and Wanninger 2015). In all investigated gymnolaemates, except for Nolella dilatata, the number of intertentacular pits, which show such a serotonin-lir signal, corresponds to the number of tentacles minus two (Schwaha and Wanninger 2015).

\section{Tentacle sheath innervation}

In addition to the innervation of the tentacle sheath itself, the neurite bundles associated with the tentacle sheath furthermore connect the peripheral nervous system to the cerebral ganglion. In gymnolaemates, tentacle sheath innervation comprises a direct tentacle sheath neurite bundle, emerging distally of the cerebral ganglion, that joins a branch of the trifid nerve, which projects more proximally of the ganglion, to form a compound tentacle sheath nerve (Lutaud 1977; Gruhl and Schwaha 2015). The observed innervation pattern in Pherusella sp. is identical. A tentacle sheath ring neurite bundle is present close to the cerebral ganglion and mostly does not form a complete ring in gymnolaemates. It shows serotonin-like immunoreactivity in Pherusella sp. as observed in Flustrelidra hispida and Amathia gracilis (Schwaha and Wanninger 2015; Temereva and Kosevich 2016).

\section{Visceral innervation}

In Pherusella sp., the same general setup of visceral neurite bundles was observed as previously reported for most other gymnolaemates. Five neurite bundles branch off from the proximal part of the cerebral ganglion and proceed along the foregut as far as the cardiac valve: paired latero-visceral and medio-lateral visceral neurite bundles, and a single more prominent medio-visceral neurite bundle (Lutaud 1977; Mukai et al. 1997). However, in the ctenostome Paludicella articulata (Ehrenberg, 1831), the medio-lateral neurite bundles are not symmetrically arranged and the number varies between zooids from three to five (Weber et al. 2014). The stomach and hindgut area in all investigated bryozoans show, if any, a very loose innervation which correlates with the sparse musculature of the digestive tract (Schwaha 2019a).

\section{Aperture and parietal innervation}

The peripheral nervous system including the apertural and parietal region is innervated by the compound tentacle sheath neurite bundle in gymnolaemates. The compound tentacle sheath neurite bundle (CTS) gives rise to several branches that innervate the diaphragm, aperture, parietal muscles, and the body wall (Gruhl and Schwaha 2015; Schwaha 2019a). In the cheilostome Electra pilosa (Linnaeus, 1767), three main branches of the CTS innervate the aperture area and the parietal musculature (Lutaud 1977). The general arrangement of the peripheral innervation pattern is thus similar between E. pilosa and Pherusella sp. with few differences: Neurite bundles in association with the diaphragmatic sphincter were not encountered in Pherusella sp. Either Pherusella sp. does not possess such neurite bundles (along with the different structure of the diaphragm) or the differences are methodological. The ramifications of the neurite bundles at the level of the vestibular wall and at the disto-lateral cystid wall in Pherusella sp. are reminiscent of the distal branches in E. pilosa. The innervation of the parietal musculature is similar in both species, too. Single neurite bundles proceed toward each parietal muscle bundle, although in Pherusella sp. the branches ramify already at the parietal plexus before bending in the proximal direction, whereas in E. pilosa, ramification of the neurite bundle occurs later, distally of the parietal muscle bundles. From the branch of the neurite bundle that proceeds toward the parietal muscles, some neurite bundles proceed toward the frontal wall to innervate the marginal spines in E. pilosa. Ctenostomes such as Pherusella lack marginal spines, but similar neurite bundles proceed frontally to innervate the frontal wall in Pherusella sp. In the alcyonidioid ctenostome Alcyonidium polyoum, a similar traverse of such neurite bundles was encountered (Lutaud 1977, 1981). 


\section{Conclusion and outlook}

Novel data on the life cycle of Pherusella sp. revealed an adapted life style to a life on seagrass leaves, such as short generation time and a constant production of larvae to recolonize unvegetated parts of the seagrass throughout the year. Pherusella sp. is only the fourth reported bryozoan species to possess a pseudocyphonautes larva. Larval settlement experiments and cultivation under laboratory conditions provide the first information on metamorphosis for this member of the Pherusellidae. Concerning the musculature, this study shows there are several similarities within the ctenostomes and gymnolaemates in the general architecture. Differences were encountered as in the apertural and lophophoral musculature, which might be of functional nature or aid in future phylogenetic reconstructions. Most studies on the adult bryozoan nervous systems have so far focused on the lophophoral base and the tentacle innervation; this study is one of the few that also provides data on the peripheral nervous system and the innervation of the parietal musculature. Data on peripheral nervous system might aid in future studies in interzooidal communication. Taken together, this work adds important morphological and developmental data on a poorly investigated group of bryozoans. New morphological data supports previous assumptions that pherusellids are closely related to other alcyonidioideans. A distinct character evolution analysis among ctenostomes, however, awaits a more comprehensive and complete phylogenetic reconstruction of ctenostome bryozoans.

Acknowledgments Thanks to Meeresschule Pula and its supporting team for advice and for providing laboratory infrastructure. SHD thanks the following people for the aid in the fieldwork of the Meeresschule: Simone Raus, Sandra Bracun, Johannes Maximilian Salvenmoser, Maximilian Loimer, Georg Winkler, and Jasper Jung.

Funding Information Open access funding provided by University of Vienna.

Data availability Data is available from the corresponding author upon reasonable request.

Open Access This article is licensed under a Creative Commons Attribution 4.0 International License, which permits use, sharing, adaptation, distribution and reproduction in any medium or format, as long as you give appropriate credit to the original author(s) and the source, provide a link to the Creative Commons licence, and indicate if changes were made. The images or other third party material in this article are included in the article's Creative Commons licence, unless indicated otherwise in a credit line to the material. If material is not included in the article's Creative Commons licence and your intended use is not permitted by statutory regulation or exceeds the permitted use, you will need to obtain permission directly from the copyright holder. To view a copy of this licence, visit http://creativecommons.org/licenses/by/4.0/.

\section{References}

Bobin, G. (1977). Interzooecial communications and the funicular system. In R. M. Woollacott \& R. L. Zimmer (Eds.), Biology of bryozoans (pp. 307-333). New York: Academic Press.
Bock, P., \& Gordon, D. P. (2013). Phylum Bryozoa Ehrenberg, 1831. Zootaxa, 3703, 67-74.

Brancato, M. S., \& Woollacott, R. M. (1982). Effect of microbial films on settlement of bryozoan larvae (Bugula simplex, B. stolonifera and B. turrita). Marine Biology, 71, 51-56.

Chimenz Gusso, C., \& D'Hondt, J. L. (2005). Finding of Pherusella brevituba Soule, 1951 (Bryozoa Ctenostomatida, Pherusellidae) in the Mediterranean Sea. Bollettino del Museo Civico di Storia Naturale di Verona, 29, 85-88.

Chimenz Gusso, C., Boccia, P., \& Giovanni, N. (2004). Importance of faunistic and taxonomical studies for a correct analysis of the zoogeography of Mediterranean Bryozoa. Biogeographia, 25, 93-108.

D'Hondt, J. L. (1983). Tabular keys for identification of the recent Ctenostomatous Bryozoa. Mémoires de L'Institut Océanographique, Monaco, 14, 1-134.

Eggleston, D. (1972). Patterns of reproduction in the marine Ectoprocta of the Isle of Man. Journal of Natural History, 6, 31-38.

Gordon, D. P. (1970). Reproductive ecology of some northern New Zealand Bryozoa. Cahiers de Biologie Marine, 11, 307-323.

Gordon, D. P. (1974). Microarchitecture and function of the lophophore in the bryozoan Cryptosula pallasiana. Marine Biology, 27, 147163.

Gordon, D. P. (1977). The ageing process in bryozoans. In R. M. Woollacott \& R. L. Zimmer (Eds.), Biology of bryozoans (pp. 335-376). New York: Academic Press.

Gruhl, A. (2019). Larval structure and metamorphosis. In T. Schwaha (Ed.), Handbook of zoology, Bryozoa. Berlin: de Gruyter.

Gruhl, A., \& Schwaha, T. (2015). Bryozoa. In A. Schmidt-Rhaesa, S. Harzsch, \& G. Purschke (Eds.), Structure and evolution of invertebrate nervous system (pp. 325-340). Oxford: Oxford University Press.

Hayward, P. J. (1985). Ctenostome Bryozoans. (synopsis of the British Fauna (new series) no. 33). London, Leiden, Köln, Kobenhavn: E.J. Brill/Dr.W. Backhuys for The Linnean Society of London \& The Estuarine and Brackish-Water Sciences Association.

Hyman, L. H. (1959). The invertebrates (Vol. V. Smaller coelomate groups, p. 783). New York: McGraw-Hill.

Jebram, D. (1973a). Stolonen-Entwicklung und Systematik bei den Bryozoa Ctenostomata. Zeitschrift für zoologische Systematik \& Evolutionsforschung, 11, 1-48.

Jebram, D. (1973b). The importance of different growth directions in the Phylactolaemata and Gymnolaemata for reconstructing the phylogeny of the Bryozoa. In G. P. Larwood (Ed.), Living and fossil Bryozoa (pp. 565-576). London: Academic Press.

Jebram, D. (1986). The ontogenetical and supposed phylogenetical fate of the parietal muscles in the Ctenostomata (Bryozoa). Zeitschrift für zoologische Systematik \& Evolutionsforschung, 24, 58-82.

Kvach, A.Y., Varfolomeeva, M., Kotenko, O. N., Sukhotin, A., Kutiumov, V. A, Grischenko, A. V., Granovitch, A. I., \& Ostrovsky, A. N. (2019) Life history of the ctenostome bryozoan Flustrellidra hispida in the White Sea. Invertebrate Zoology 16 :343-360

Lutaud, G. (1977). The bryozoan nervous system. In R. M. Woollacott \& R. L. Zimmer (Eds.), Biology of bryozoans (pp. 377-410). New York: Academic press.

Lutaud, G. (1981). The innervation of the external wall in the carnosan ctenostome Alcyonidium polyoum (Hassall). In G. P. Larwood \& C. Nielsen (Eds.), Recent and fossil Bryozoa (pp. 143-150). Olsen \& Olsen: Fredensborg.

Matricon, I. (1963). Dégénérescence du polypide femelle et formation d'une poche incubatrice chez Alcyonidium polyoum (Hassall) (Bryozaire Cténostome). Archives Zoologie expérimentale et générale, 102, 79-93.

Mukai, H., Terakado, K., \& Reed, C. G. (1997). Bryozoa. In F. W. Harrison \& R. M. Woollacott (Eds.), Microscopic anatomy of invertebrates (Vol. 13, pp. 45-206). New York: Wiley-Liss. 
Nielsen, C. (1971). Entoproct life-cycles and the entoproct/ectoproct relationship. Ophelia, 9, 209-341.

Ostrovsky, A. N. (2013). Evolution of sexual reproduction in marine invertebrates: example of gymnolaemate bryozoans (356 p). Dordrecht, Heidelberg, New York, London: Springer.

Ostrovsky, A. N. (2019). Sexual reproduction in Bryozoa. In T. Schwaha (Ed.), Handbook of zoology. Bryozoa. Berlin: de Gruyter.

Prado, P., Alcoverro, T., \& Romero, J. (2008). Seasonal response of Posidonia oceanica epiphyte assemblages to nutrient increase. Marine Ecology Progress Series, 359, 89-98.

Pröts, P., Wanninger, A., \& Schwaha, T. (2019). Life in a tube: morphology of the ctenostome bryozoan Hypophorella expansa. Zoological Letters, 5, 28. https://doi.org/10.1186/s40851-019-0142-2.

Prouho, H. (1892). Contribution à l'histoire des Bryozaires. Archives Zoologie expérimentale et générale (2nd series), 10, 557-656.

Reed, C. G. (1987). Bryozoa. In M. F. Strathmann (Ed.), Reproduction and development of marine invertebrates of the northern Pacific coast: data and methods for the study of eggs, embryos, and larvae (pp. 494-510). Seatlle: University of Washington Press.

Reed, C. G. (1991). Bryozoa. In A. C. Giese, J. S. Pearse, \& V. B. Pearse (Eds.), Reproduction of marine invertebrates. VI. Echinoderms and lophophorates (pp. 85-245). Pacific Grove: The Boxwood Press.

Reed, C. G., \& Cloney, R. A. (1982). The settlement and metamorphosis of the marine bryozoan Bowerbankia gracilis (Ctenostomata: Vesicularioidea). Zoomorphology, 101, 103-132.

Riedl, R. (1983). Tentaculata. In Fauna und Flora des Mittelmeers (pp. 559-576).

Rosso, A., \& Di Martino, E. (2016). Bryozoan diversity in the Mediterranean Sea: an update. Mediterranean Marine Science, 17, 801-802.

Ryland, J. S. (1959). Experiments on the selection of algal substrates by polyzoan larvae. Journal of Experimental Biology, 36, 613-631.

Ryland, J. S. (1970). Bryozoans. London: Hutchinson University Library.

Ryland, J. S. (2005). Bryozoa: an introductory overview. Denisia, 19, 9-20.

Schindelin, J., Arganda-Carreras, I., Frise, E., Kaynig, V., Longair, M., Pietzsch, T., Preibisch, S., Rueden, C., Saalfeld, S., Schmid, B., Tinevez, J. Y., White, D. J., Hartenstein, V., Eliceiri, K., Tomancak, P., \& Cardona, A. (2012). Fiji: an open-source platform for biological-image analysis. Nature Methods, 9, 676-682. https:// doi.org/10.1038/nmeth.2019.

Schwaha, T. (2019a). Morphology of bryozoans. In T. Schwaha (Ed.), Handbook of zoology: Bryozoa. Berlin: DeGruyter.

Schwaha, T. (2019b). Ctenostomata. In T. Schwaha (Ed.), Handbook of zoology. Bryozoa. Berlin: de Gruyter.

Schwaha, T.F., \& Wanninger, A. (2015). The serotonin-lirnervous system of the Bryozoa (Lophotrochozoa): a general pattern in the Gymnolaemata and implications for lophophore evolution of the phylum. BMC Evolutionary Biology, 15, 223. https://doi.org/10.1186/s12862-015-0508-9.
Schwaha, T., \& Wanninger, A. (2018). Unity in diversity: a survey of muscular systems of ctenostome Gymnolaemata (Lophotrochozoa, Bryozoa). Frontiers in Zoology, 15, 24.

Schwaha, T., Handschuh, S., Redl, E., \& Walzl, M. (2011). Organogenesis in the budding process of the freshwater bryozoan Cristatella mucedo Cuvier 1789 (Bryozoa, Phylactolaemata). Journal of Morphology, 272, 320-341.

Schwaha, T., Ostrovsky, A. N., \& Wanninger, A. (2020). Key novelties in the evolution of aquatic colonial phylum Bryozoa: evidence from soft body morphology. Biological Reviews, 95, 696-729.

Silen, L. (1966). On the fertilization problem in the gymnolaematous Bryozoa. Ophelia, 3, 113-140.

Soule, J. D. (1951). Two new species of encrusting ctenostomatous Bryozoa from the Pacific. Journal of the Washington Academy of Sciences, 41, 367-370.

Soule, J. D. (1953). Post-larval development in Carnosa (Bryozoa Ctenostomata). Bull. S. Calif. Acad. Aci., 52, 88-92.

Ström, R. (1977). Brooding patterns of bryozoans. In R. M. Woollacott \& R. L. Zimmer (Eds.), Biology of bryozoans (pp. 23-55). New York: Academic Press.

Temereva, E. N., \& Kosevich, I. A. (2016). The nervous system of the lophophore in the ctenostome Amathia gracilis provides insight into the morphology of ancestral ectoprocts and the monophyly of the lophophorates. BMC Evolutionary Biology, 16, 181. https://doi.org/ 10.1186/s12862-016-0744-7.

Todd, J. A. (2000). The central role of ctenostomes in bryozoan phylogeny. In A. Herrera Cubilla \& J. B. C. Jackson (Eds.), Proceedings of the 11th international bryozoology association conference (pp. 104-135). Balboa: Smithsonian Tropical Research Institute.

Waeschenbach, A., Taylor, P. D., \& Littlewood, D. T. J. (2012). A molecular phylogeny of bryozoans. Molecular Phylogenetics and Evolution, 62, 718-735. https://doi.org/10.1016/j.ympev.2011.11.011.

Weber, A., Wanninger, A., \& Schwaha, T. (2014). The nervous system of Paludicella articulata - first evidence of a neuroepithelium in a ctenostome ectoproct. Frontiers in Zoology, 11, 89.

Zabala, M., \& Maluquer, P. (1988). Illustrated keys for the classification of Mediterranean Bryozoa. Treballs del Museu de Zoologia, Barcelona, 4, 1-294.

Zimmer, R. L., \& Woollacott, R. M. (1977a). Structure and classification of gymnolaemate larvae. In R. M. Woollacott \& R. L. Zimmer (Eds.), Biology of bryozoans (pp. 57-90). New York: Academic Press.

Zimmer, R. L., \& Woollacott, R. M. (1977b). Metamorphosis, ancestrulae and coloniality in bryozoan life cycles. In R. M. Woollacott \& R. L. Zimmer (Eds.), Biology of bryozoans (pp. 91-142). New York: Academic Press.

Publisher's note Springer Nature remains neutral with regard to jurisdictional claims in published maps and institutional affiliations. 